\title{
Peroxisome deficient invertebrate and vertebrate animal models
}

\author{
Paul P. Van Veldhoven ${ }^{1 *}$ and Myriam Baes ${ }^{2 *}$ \\ 1 LIPIT, Department Cellular and Molecular Medicine, KU Leuven, Leuven, Belgium \\ ${ }^{2}$ Laboratory of Cellular Metabolism, Department of Pharmaceutical and Pharmacological Sciences, KU Leuven, Leuven, Belgium
}

\author{
Edited by: \\ Richard Rachubinski, University of \\ Alberta, Canada \\ Reviewed by: \\ Giovanni Solinas, University of \\ Fribourg, Switzerland \\ Qihan Dong, The University of \\ Sydney, Australia \\ *Correspondence: \\ Paul P. Van Veldhoven, LIPIT, \\ Department Cellular and Molecular \\ Medicine, KU Leuven, Campus \\ Gasthuisberg, O\&N1, Herestraat \\ Box 601, B-3000, Leuven, Belgium \\ e-mail:paul.vanveldhoven@ \\ med.kuleuven.be; \\ Myriam Baes, Laboratory of Cellular \\ Metabolism, KU Leuven, Campus \\ Gasthuisberg, O\&N2, Herestraat \\ Box 823, B-3000 Leuven, Belgium \\ e-mail:myriam.baes@ \\ pharm.kuleuven.be
}

Although peroxisomes are ubiquitous organelles in all animal species, their importance for the functioning of tissues and organs remains largely unresolved. Because peroxins are essential for the biogenesis of peroxisomes, an obvious approach to investigate their physiological role is to inactivate a Pex gene or to suppress its translation. This has been performed in mice but also in more primitive organisms including $D$. melanogaster, C. elegans, and D. rerio, and the major findings and abnormalities in these models will be highlighted. Although peroxisomes are generally not essential for embryonic development and organogenesis, a generalized inactivity of peroxisomes affects lifespan and posthatching/postnatal growth, proving that peroxisomal metabolism is necessary for the normal maturation of these organisms. Strikingly, despite the wide variety of model organisms, corresponding tissues are affected including the central nervous system and the testis. By inactivating peroxisomes in a cell type selective way in the brain of mice, it was also demonstrated that peroxisomes are necessary to prevent neurodegeneration. As these peroxisome deficient model organisms recapitulate pathologies of patients affected with peroxisomal diseases, their further analysis will contribute to the elucidation of still elusive pathogenic mechanisms.

\footnotetext{
Keywords: inflammation, male fertility, phytanic acid, plasmalogens, PUFA, very long chain fatty acids, Zellweger syndrome
}

\section{INTRODUCTION}

Absence of peroxisomes in man leads to a devastating disease, clinically known as the hepato-renal syndrome of Zellweger. Affected baby's are born alive, but are severely hypotonic, mentally retarded with brain malformation, liver and kidney problems, and die generally with the first weeks of life (Wanders and Waterham, 2005). Understanding the anomalies at the cellular and organ level and the malformation during development in such patients with a peroxisome biogenesis disorder, requires access to suitable experimental material. Unfortunately, for man the sources are rather limited (fibroblasts, lymphoblasts, amniotic villi), and not representative for specialized cells/tissues. In addition, no natural occurring or inducible animal model is known. Hence, as soon as appropriate molecular techniques were established, animal models were created, starting of with PEX5 ${ }^{1}$ (Baes et al., 1997) and PEX2 (Faust and Hatten, 1997)

\footnotetext{
${ }^{1}$ For the sake of consistency, the nomenclature guidelines as formulated for rodents (http://www.informatics.jax.org/mgihome/nomen/gene. shtml) are followed throughout this text, gene symbols being italicized, first letter capitalized, whereas the protein is referred to by the corresponding gene symbol in standard capitalized font. Guidelines related to nomenclature in other species can be found at following URLs: nematodes (http://www.wormbase.org/about/userguide/nomenclature\# fda31g748bjh9c650ie2-10); fruitflies (http://flybase.org/staticpages/ docs/nomenclature/nomenclature3.html\#1.2.3.); zebrafish (https://wiki. zfin.org/display/general/ZFIN+Zebrafish+Nomenclature+Guidelines\#ZFINZ ebrafishNomenclatureGuidelines-1.1); man (http://www.genenames.org).
}

deficient mice in 1997, followed later by inactivation of peroxins in other laboratory "pet-animals" like worms, fruitfly, or zebrafish.

In addition to these animal models, peroxisome deficient mutants were created in different yeasts, starting of with baker's yeast (Erdmann et al., 1989), followed by Hansenula polymorpha (Cregg et al., 1990) and Pichia pastoris (Gould et al., 1992); in filamentous fungi, Neurospora crassa (Sichting et al., 2003; Managadze et al., 2007), Magnaporthe grisea (Ramos-Pamplona and Naqvi, 2006), Aspergillus oryzae (Escano et al., 2009), in plants like Arabidopsis (Kaplan et al., 2001; Schumann et al., 2003; Fan et al., 2005), in trypanosomes (Banerjee et al., 2005; Galland et al., 2007). Some of the latter models are described elsewhere in this book, whereas for a treatise on human disorders linked to peroxisomes we refer to (Wanders and Waterham, 2005; Waterham and Ebberink, 2012).

Before discussing in more detail the different animal models, a general description of the metabolic functions of peroxisomes is given, followed by a short note about their biogenesis.

\section{PEROXISOMAL METABOLISM}

From a human pathological point of view, the main peroxisomal pathways are $\beta$-oxidation, $\alpha$-oxidation, and ether lipid synthesis, and to a lesser extent glyoxylate metabolism and xanthine metabolism. Whereas peroxisomal $\beta$-oxidation seems universally present in all animals, although sometimes serving other purposes, some of the other pathways might be missing in 
lower vertebrates/invertebrates (e.g., etherlipid synthesis). In the following paragraphs the main pathways are briefly described, whereas their specific roles, if known, will be highlighted when discussing the different models (enzymes are named according to the mouse nomenclature).

Typically, peroxisomes can $\beta$-oxidize a broad range of natural, often also xenobiotic, compounds containing a fatty acyl side chain with or without a methyl-branch, in $\alpha$-position of the carboxy-group. This process consists of a sequence of four reactions, resulting in shortening of the main chain of an acyl-CoA by 2 carbons (see Figure 1) (Van Veldhoven, 2010). In a first step, acyl-CoA is converted into 2-trans-enoyl-CoA by an acylCoA oxidase (ACOX), thereby producing $\mathrm{H}_{2} \mathrm{O}_{2}$. The number of ACOXs varies between species and ACOXs acting on 2-methylacyl-CoAs (ACOX2 and ACOX3 in mammals) are stereospecific, only the $2 \mathrm{~S}$-isoform is desaturated, hence an additional peroxisomal enzyme, 2-methylacyl-CoA racemase (AMACR), is required to convert the $2 \mathrm{R}$-isoforms. The oxidation is followed by a hydration of the double bond by a 2-enoyl-CoA hydratase, a dehydrogenation by 3-hydroxyacyl-CoA dehydrogenase, and finally a thiolytic cleavage, generating acetyl-CoA (or propionyl-CoA in case of 2-methylbranched acyl-CoA) and a shortened acyl-CoA. Generally more than one enzyme can catalyze each of these steps, either homologous proteins as is the case for ACOXs or totally different proteins, e.g., thiolases encoded by the Acaal or Scp2 genes, or activities can reside in multi-enzymes (e.g., EHHAHD, also called multifunctional protein 1 (MFP1), HSD17B4, often called MFP2), which catalyze the hydration and dehydrogenation steps in a stereoselective manner. In mammals, a well-characterized $\beta$-oxidation pathway is the formation of $\mathrm{C}_{24}$-bile acids, starting from $\mathrm{C}_{27}$-bile acids (cholestanoic acids). In lower vertebrates, such as reptiles, some amphibia, and lungfishes, however, no $\mathrm{C}_{24}$-bile acids are found (Hofmann et al., 2010). On the other hand, the genomes of amphibia, bony fishes and various invertebrates like insects, bivalves, and sea urchins (but not nematodes), encode a peroxisomal AMACR, suggestive for a role of peroxisomes in breakdown of other isoprenoid derived carboxylates in these species.

$\alpha$-Oxidation is a process whereby fatty acids are shortened by one carbon atom, amply documented for phytanic acid in man, a diet derived 3-methylbranched fatty acid, and less wellknown for long chain 2-hydroxy fatty acids (Van Veldhoven, 2010) (see Figure 2). For phytanic acid, the process starts with the hydroxylation of phytanoyl-CoA at position 2 (by phytanoyl-CoA hydroxylase, $\mathrm{PHYH}$ ), followed by a cleavage into formyl-CoA and pristanal, catalyzed by 2-hydroxyacyl-CoA lyase (HACL1). 2-Hydroxy long chain fatty acids do not depend on PHYH and are, after activation, shortened into a (n-1)fatty aldehyde by HACL1. This pathway is present in all mammals, and representative species of birds, reptiles, amphibian, fish, insects, nematodes, echinoderms, cnidaria, ascidia.

In contrast to the bulk of glycerolipids containing esterlinked fatty acids, a small portion of glycerolipids contains an ether bond, the precursor of which is formed by peroxisomal enzymes (see Figure 3). A first one, dihydroxyacetone-phosphate acyltransferase (GNPAT) generates an obligate precursor, 1-acyl-dihydroxyacetone-phosphate, a second one catalyzes the exchange of the acyl for an alcohol (alkyl dihydroxyacetonephosphate synthase, ADHAPS). After reduction, the generated 1-alkylglycerol-3-phosphate follows the same anabolic routes as 1-acylglycerol-3-phosphate in the ER, leading to neutral and phosphoglycerolipids with a 1-alkyl group. In mammals, 1-alkyl2-acylglycerophosphoethanolamine is desaturated just adjacent to the ether linkage, generating plasmenylethanolamine which can be converted to the choline analogue. Phospholipids with this vinylether group are better known as plasmalogens. Based on genomic information, the key enzymes GNPAT and ADHAPS are expressed in nematodes, cnidaria, echinoderms, insects, fish, amphibia, reptiles and birds. The presence of plasmalogens will however, depend on the expression of plasmanylethanolamine desaturase, an orphan enzyme not yet cloned. Besides mammals, plasmalogens have been identified in various animals including birds, amphibia, fish, insects, molluscs, marine worms, jelly fish, echinodermata, slime mold (Horrocks and Sharma, 1982).

Depending on species, peroxisomes or related organelles (glyoxysomes) are more or less actively involved in glyoxylate metabolism and in the degradation of purines (purine oxidation pathway or ureide pathway). Depending on the phylogenetic position of the species, purines are degraded till the level of ureum (amphibian, fish) or only till uric acid (man).

\section{PEROXISOME BIOGENESIS}

Proteins involved in the formation (biogenesis) of peroxisomes were first identified in yeast (Erdmann et al., 1989), and the major players in this process are rather well-conserved throughout the different kingdoms. In yeast and lower eukaryotes, however, more peroxins are found that are involved in fission/fusion processes and regulation of the number of peroxisomes ${ }^{2}$, which is related to the fact that these species must be able to adapt their intracellular organelles quickly to changes in their environment. Briefly for animals, peroxisomal matrix proteins, synthesized in the cytosol, are captured by binding partners that recognize a specific motif within their primary sequence, either a C-terminal tripeptide, better known as Peroxisome Targeting Signal 1 (PTS1) which is recognized by PEX5, or an N-terminal nonapeptide (PTS2), bound by PEX7 (see Figure 4). Upstream residues of PTS1, often referred to as SKL-sequence, influence binding to Pex5, hence a more in depth analysis of the interaction has broadened PTS1 to a dodecamer (Brocard and Hartig, 2006). In all species investigated, only a minority of matrix proteins contain PTS2, and in certain species, such as nematodes (C. elegans; Motley et al., 2000), diatoms (Phaeodactylum tricornutum; Gonzalez et al., 2011), and insects (Drosophila; Faust et al., 2012), PEX7 is even missing. In those organisms, the classical PTS2 proteins are still associated with peroxisomes, but are decorated with PTS1 (de Vet et al., 1998; Motley et al., 2000; Faust et al., 2012).

PEX5-PTS1 cargoes dock to the peroxisomal membrane via PEX14/PEX13, and are subsequently translocated through the bilayer. At the matrical side of the membrane, the cargo is released

\footnotetext{
${ }^{2}$ In sensu stricto of the original definition (Distel et al., 1996), these proteins should not be called peroxins.
} 

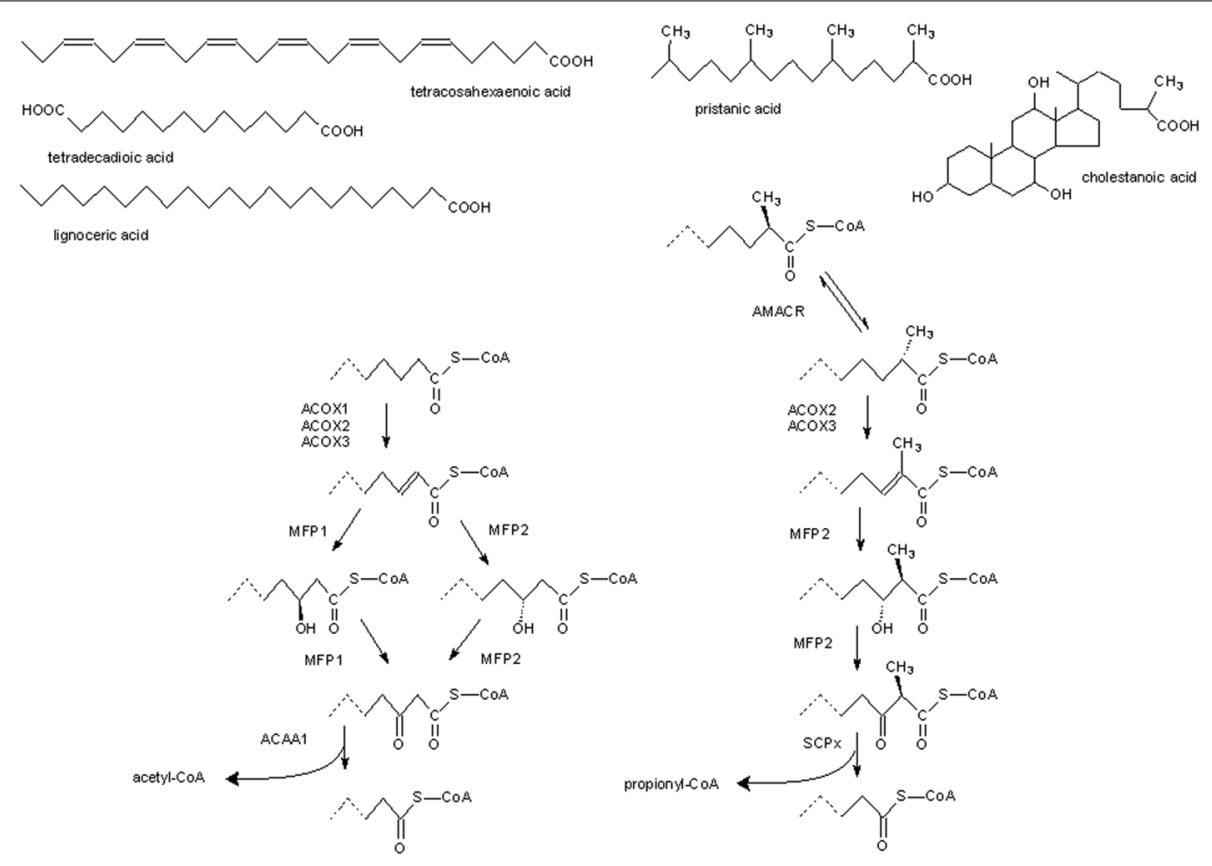

FIGURE 1 | Generalized scheme of peroxisomal $\beta$-oxidation in animals. On top, structures of some fatty carboxylates that, after activation (not shown), are degraded by peroxisomal $\beta$-oxidation. At the right, enzymatic reactions/enzymes involved in degradation of substrates containing a

2-methylbranch, based on the situation in mammals. Most of these enzymes can act on straight chain substrates, shown at the left, as well. The latter compounds are also recognized by more selective enzymes which do not tolerate a 2-methylbranch. ACAA1, 3-ketoacyl-CoA thiolase; ACOX, acyl-CoA oxidase; AMACR, 2-methylacyl-CoA racemase; MFP, multifunctional protein; SCPx, sterol carrier protein $\mathrm{X}$-thiolase.

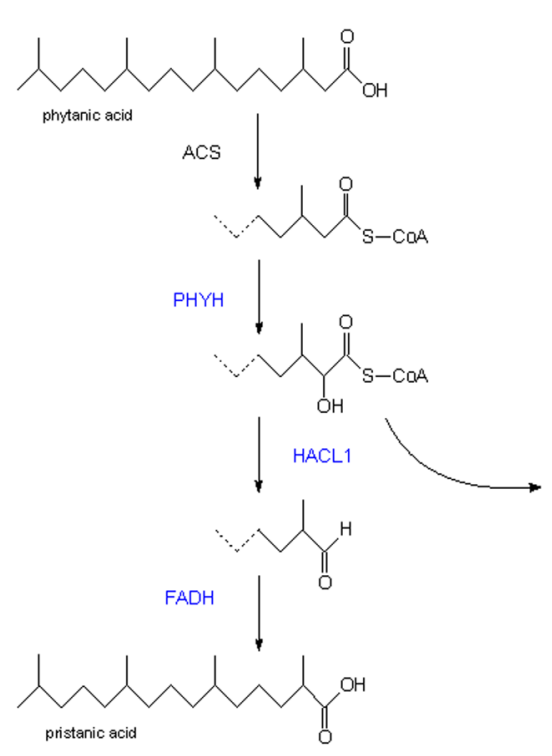

FIGURE 2 | Peroxisomal $\alpha$-oxidation. Scheme of the enzymatic reactions/enzymes involved in the peroxisomal breakdown of phytanic acid (left) and 2-hydroxy long chain fatty acids (right). Enzymes in blue are
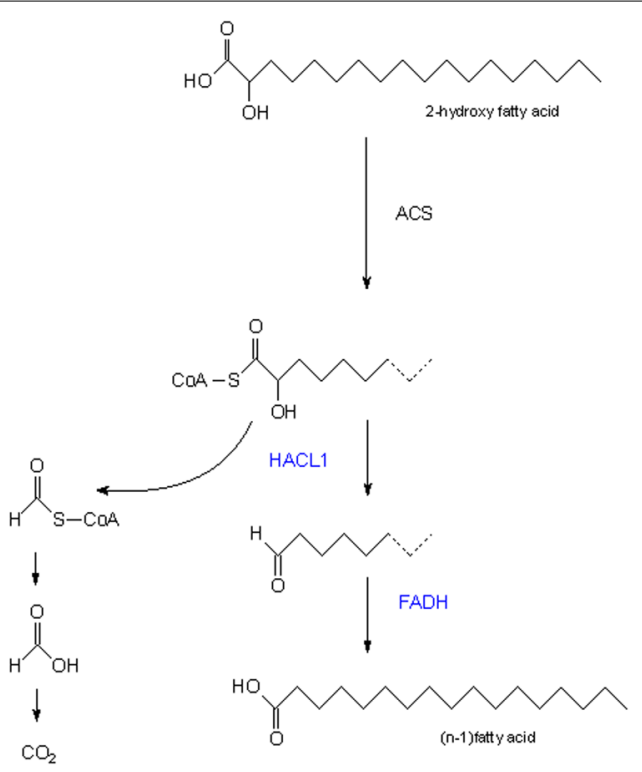

associated with peroxisomes. ACS, acyl-CoA synthetase; FADH, fatty aldehyde dehydrogenase; HACL1, 2-hydroxyacyl-CoA lyase; PHYH, phytanoyl-CoA $\alpha$-hydroxylase. and PEX5 recycles to the membrane where it will undergo ubiquitination mediated by the RING-finger proteins PEX2, PEX10, and PEX12, and extracted back to the cytosol via PEX1/PEX6 in an ATP-dependent manner.
PEX7-PTS2 cargo also binds to PEX14, not directly but mediated via a long isoform of PEX5 (PEX5L) in mammals and other vertebrates (Figure 4). In fungi, the function of the latter is taken over by PEX18/PEX21 (Dodt et al., 2001). 


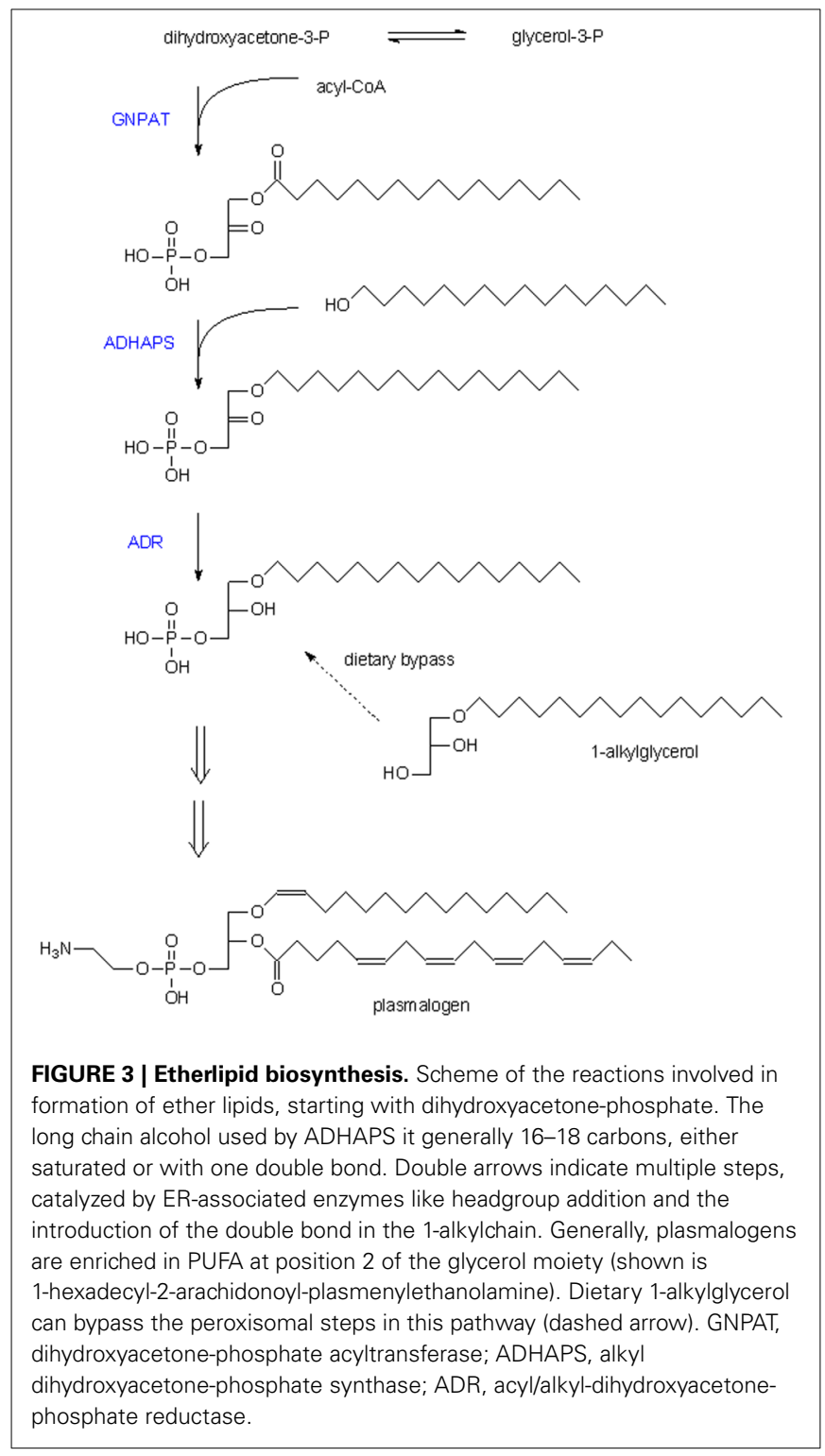

Membrane biogenesis is depending on PEX19, PEX3, and (in animals) PEX16 (Fujiki et al., 2006). PEX19, a mainly cytosolic protein, plays a chaperone like function and binds most newly synthesized integral peroxisomal membrane proteins (PMP), and docks to PEX3, an integral peroxisomal membrane protein.

Finally, size and abundance of peroxisomes are regulated by PEX11 proteins, which play also a role in elongation of the organelles (Thoms and Erdmann, 2005; Koch et al., 2010). In mammals three isoforms are known, in lower animals only one (Table 1).

\section{MODELS}

In the following sections, laboratory animals in which peroxisome biogenesis has been studied will be described. In Table 1, gene symbols and alternative names for peroxins in these animals are listed. Given differences in life cycle and organogenesis, the development of these animals will be shortly described, and

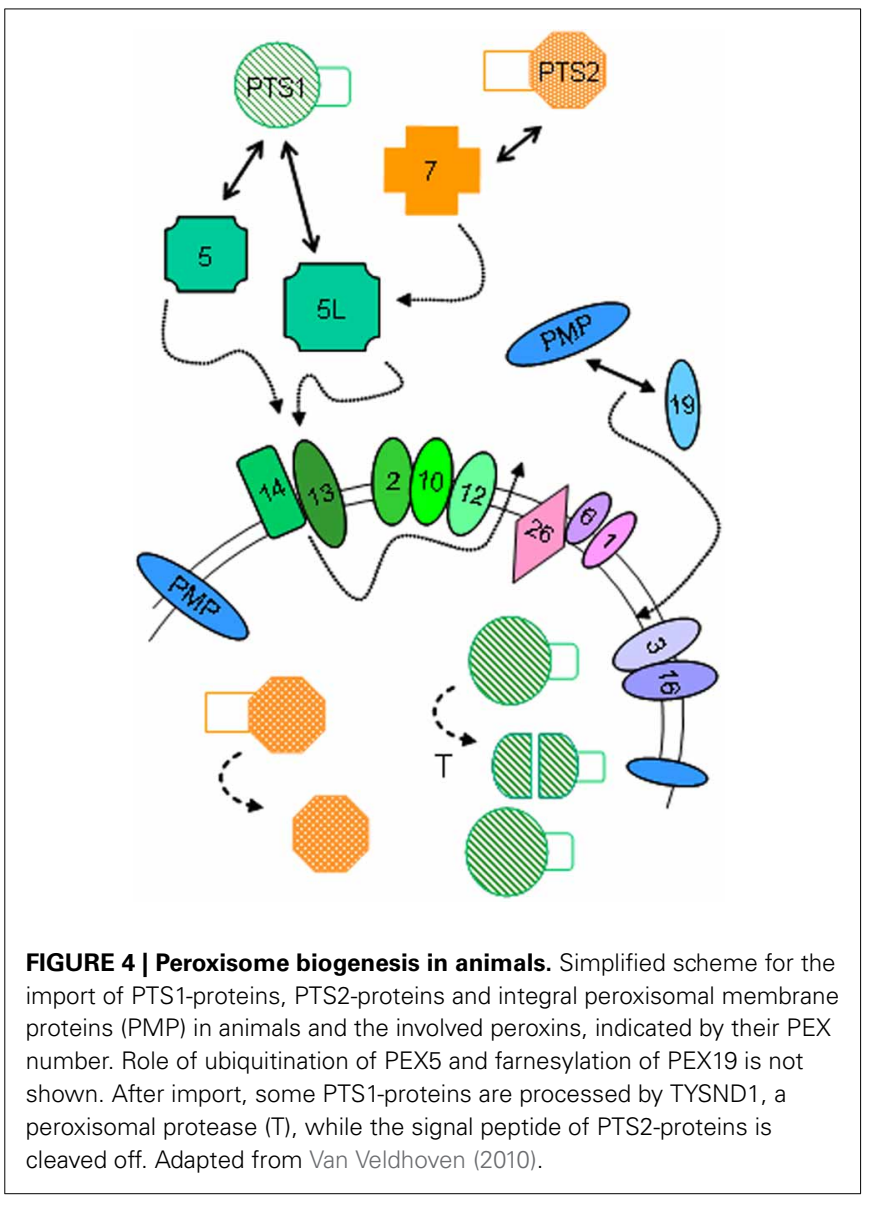

specific metabolic roles of peroxisomes, if documented, will be highlighted.

\section{NEMATODES}

A fertilized Caenorhabditis elegans egg develops into a small worm within the shell, in about 10-12 h. In the preceding $6 \mathrm{~h}$ (organogenesis/morphogenesis stage), the spheroid embryo started to elongate while its three germ layers differentiate into organs. After hatching, the post-embryonic development will start and the animal will pass, if food is present, through four larval stages (L1-L4, separated by $7-9 \mathrm{~h}$ ) to reach sexual maturation, generally as a hermaphrodite, about $1.2 \mathrm{~mm}$ long, and will start to produce eggs. The cycle from egg to egg is therefore about 3 days; life span of the worm is 2 weeks.

In the adult nematode, peroxisomes are mainly present in the epithelial cells of the digestive tract, one of the largest organs, and in the pharyngeal gland (Yokota et al., 2002). In the gut, their volume density is $1.86 / 100 \mu \mathrm{m}^{2}$ cytoplasm, similar to that in rat liver. Similar to rodents, fibrates increase the number of peroxisomes (Yokota et al., 2002). Based on the fluorescence pattern of animals expressing CFP-SKL, larvae contain more and larger peroxisomes than adult worms (Petriv et al., 2002).

In $C$. elegans, peroxisomal $\beta$-oxidation serves to generate acyl-CoAs used for the synthesis of dauer pheromone, also called daumone, a mixture of ascarosides which are excreted 
Table 1 | Overview of peroxins in animals used for peroxisomal research and in man.

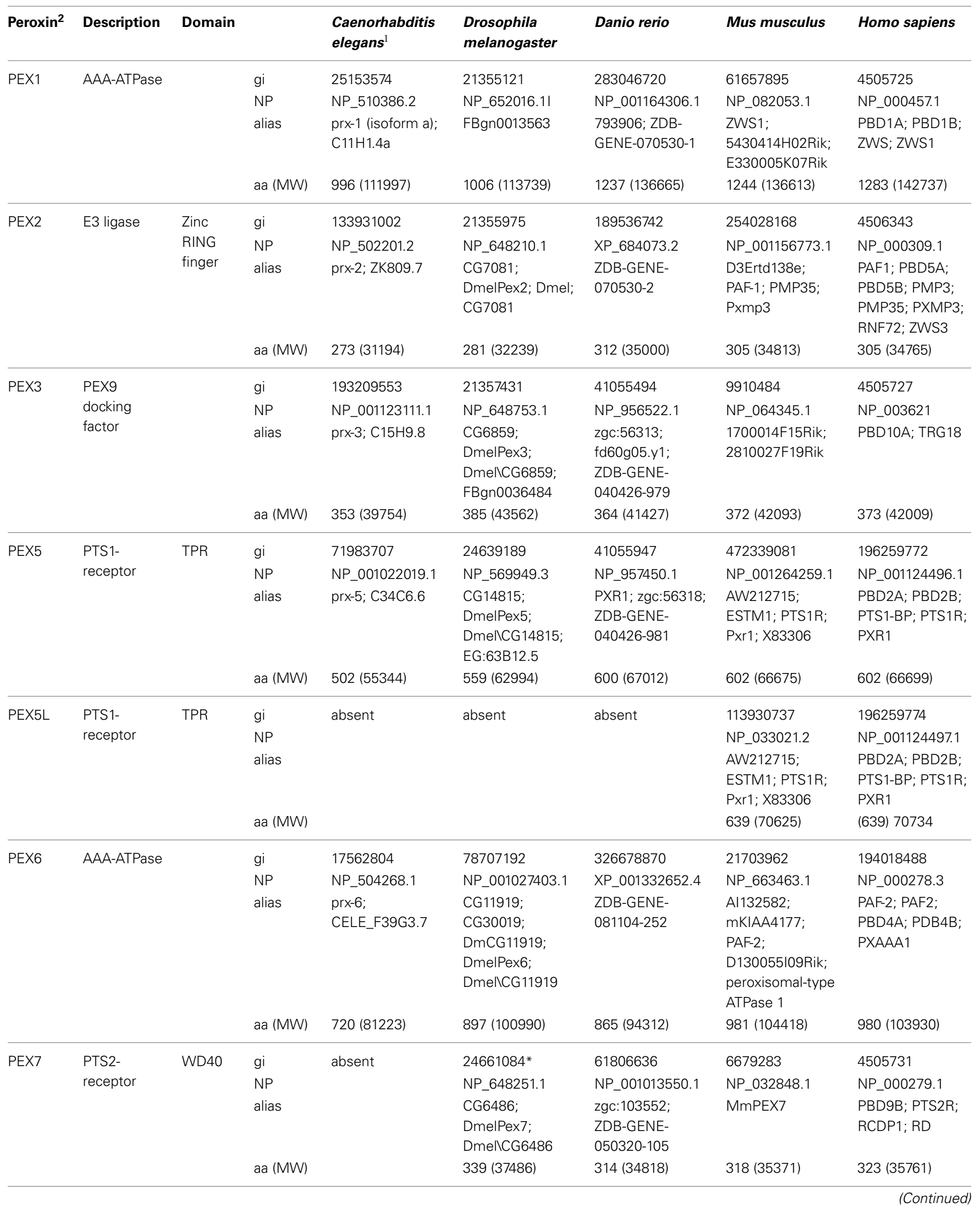


Table 1 | Continued

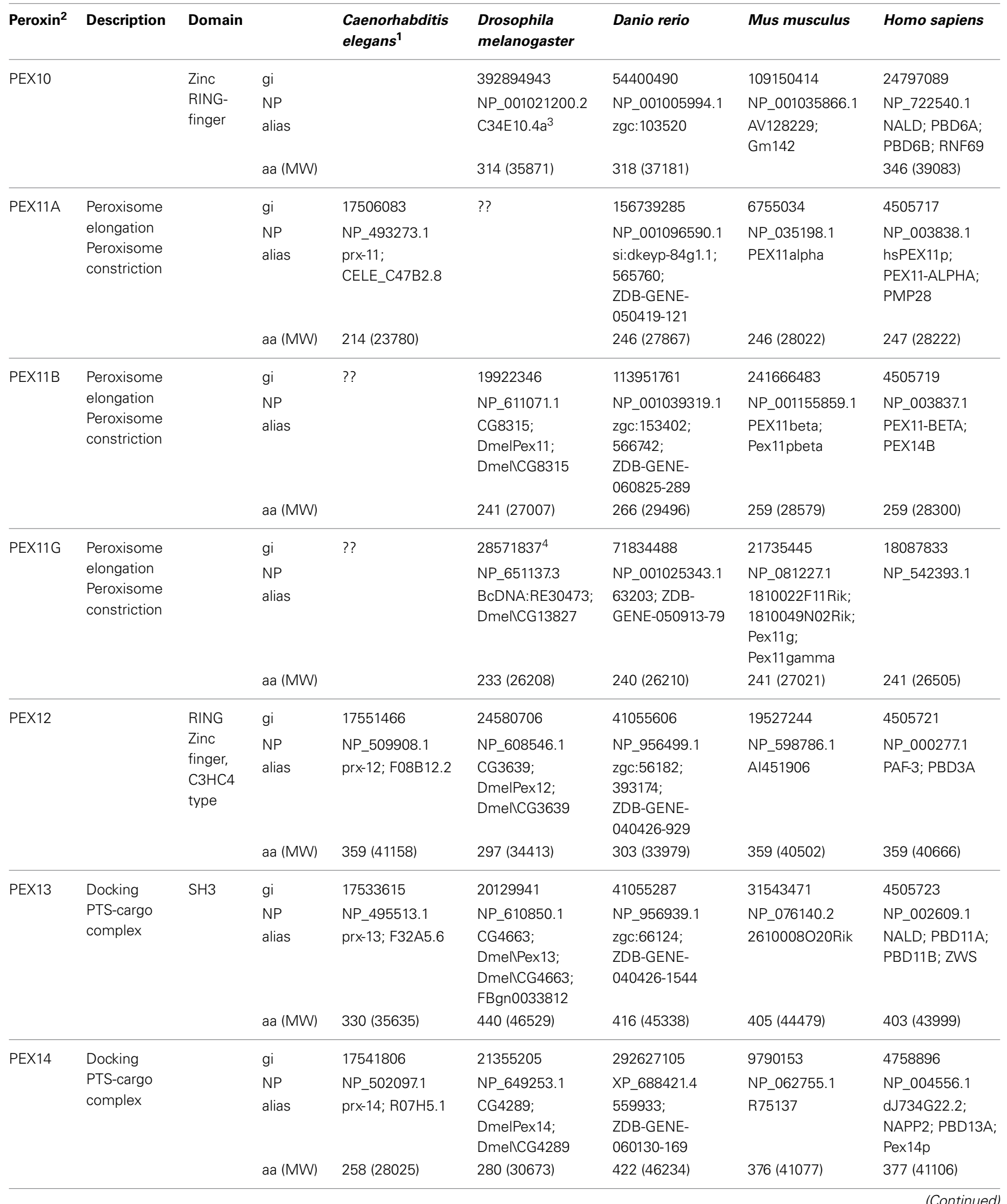


Table 1 | Continued

\begin{tabular}{|c|c|c|c|c|c|c|c|c|}
\hline Peroxin $^{2}$ & Description & Domain & & $\begin{array}{l}\text { Caenorhabditis } \\
\text { elegans }^{1}\end{array}$ & $\begin{array}{l}\text { Drosophila } \\
\text { melanogaster }\end{array}$ & Danio rerio & Mus musculus & Homo sapiens \\
\hline \multirow[t]{2}{*}{ PEX16 } & & & gi & Absent & 21355481 & 68448487 & 254750742 & 254750742 \\
\hline & & & alias & & $\begin{array}{l}\text { CG3947; } \\
\text { DmelPex16; } \\
\text { DmellCG3947 }\end{array}$ & $\begin{array}{l}\text { im:6894523; } \\
\text { zgc:112248 }\end{array}$ & & PBD8A; PBD8B \\
\hline \multirow[t]{3}{*}{ PEX19 } & \multirow{3}{*}{$\begin{array}{l}\text { Cytosolic } \\
\text { chaperone; } \\
\text { PMP import } \\
\text { receptor }\end{array}$} & \multirow{3}{*}{$\begin{array}{l}\text { CAAX- } \\
\text { box }\end{array}$} & gi & 17553610 & 24583827 & 62899043 & 226958490 & 4506339 \\
\hline & & & NP & NP_498947.1 & NP_609547.2 & NP_001017399.1 & NP_075528.3 & NP_002848.1 \\
\hline & & & alias & F54F2.8 & BEST:GH03076; & wu:fb40d12; & Pxf & D1S2223E; \\
\hline \multirow[t]{8}{*}{ PEX20 } & \multirow{8}{*}{$\begin{array}{l}\text { Cytosolic } \\
\text { chaperone }\end{array}$} & & gi & $? ?$ & 386768875 & Absent & Absent & Absent \\
\hline & & & NP & & NP_001245818.15 & & & \\
\hline & & & alias & & CG3696; & & & \\
\hline & & & & & DmelPex20; & & & \\
\hline & & & & & DmellCG3696; & & & \\
\hline & & & & & EK2-4; kis; & & & \\
\hline & & & & & $\mathrm{Su}\left(\mathrm{PC}_{\mathrm{C}}\right) 21 \mathrm{AB}$ & & & \\
\hline & & & aa (MW) & & $5343(575803)$ & & & \\
\hline PEX23 & $\begin{array}{l}\text { Peroxisome } \\
\text { proliferation; } \\
\text { peroxisomal } \\
\text { growth } \\
\text { regulation }\end{array}$ & & gi & Absent & 24667330 & Absent & Absent & Absent \\
\hline \multirow[t]{6}{*}{ PEX26 } & \multirow{6}{*}{$\begin{array}{l}\text { Anchor for } \\
\text { PEX1 and } \\
\text { PEX6 to } \\
\text { peroxisome } \\
\text { membrane }\end{array}$} & & gi & $? ?$ & $? ?$ & 41053983 & 21311973 & 189083737 \\
\hline & & & NP & $? ?$ & $? ?$ & NP_956214.1 & NP_083006.1 & NP_001121121.1 \\
\hline & & & alias & & & fk41g06; & $\begin{array}{l}\text { 4632428M11Rik; } \\
\text { Al853212 }\end{array}$ & $\begin{array}{l}\text { PBD7A; PBD7B; } \\
\text { PEX26M1T. }\end{array}$ \\
\hline & & & & & & zgc:64014 & & Pex26pM1T; \\
\hline & & & & & & & & FLJ20695 \\
\hline & & & aa (MW) & & & $313(34257)$ & 305 (33885) & 305 (33767) \\
\hline
\end{tabular}

${ }^{1}$ It should be noted that in the Worm database, prx-number has been proposed as acronym for peroxisome assembly factors given confusion with pex (pachytene exit defect). However, various entries related to prx are linked to both PeroxidoRedoXins and PeRoXisome assembly factors, given use of similar acronym.

${ }^{2}$ Peroxins, not present in animals, include PEX4, PEX8, PEX15, PEX17, PEX18, PEX21, PEX22, PEX25, PEX27, PEX28, PEX29, PEX30, PEX31, PEX32, PEX34 (all present in yeasts), PEX9, PEX20, PEX23 (Yarrowia sp.), PEX24 (yeasts, plants), PEX33 (Neurospora sp.).

${ }^{3}$ The C34E10.4 locus produces a primary transcript coding for two different proteins, PEX10 (at the 5'; C34E10.4a) or WARS-2 (at the 3'; C34E10.4b).

${ }^{4}$ In addition to this entry, another PEX11 like protein (201 amino acids, MW 22671) is encoded by the fly genome. It concerns NP_995800.1 (gi 45552555), also named CG33474; Dme/CG33474, which is most similar to PEX11G.

${ }^{5}$ One of the six different isoforms encoded by CG3696, nowadays referred to as kismet; homologous to the human CHD7 (chromodomain-helicase-DNA-binding protein 7).

${ }^{6}$ Whether NP-730508. 1 represents the counterpart of Yarrowia PEX23 or yeast PEX31 is questionable; they all contain a Dysferlin domain, but likely this entry is the counterpart of TECP1 (tectonin beta-propeller repeat-containing protein 1).

?? not present in database, likely absent.

*homologue, but functionality not proven. 
when the larvae are exposed to a hostile environment to block further development. Ascarosides are glycolipids and, in the case of dauer pheromone, consist of a hydroxylated medium chain fatty acid such as 6-hydroxyheptanoic acid or 8-hydroxy-2-nonenoic acid, O-glycosidically linked to ascarylose (3,6-didesoxymannose). Particularly daf-22 and dhs-28 (Butcher et al., 2009; Joo et al., 2009), the nematode counterparts of SCPX and the dehydrogenase moiety ${ }^{3}$ of D-specific MFP2, respectively, and acox-1 (Joo et al., 2010), one the seven nematodal ACOX proteins, are required for dauer pheromone production.

Regarding peroxisome biogenesis, it should be mentioned that the genome of $C$. elegans (and other nematodes) does not encode PEX7 (Motley et al., 2000). According to Thieringer et al. (2003) PEX16 is also missing and only one PEX11 isoform is present (Table 1).

During various large screenings by RNAi soaking, feeding or injection experiments, different peroxins were hit, however, the phenotype of the offspring was only minimally scored and the efficacy of silencing not investigated (see Table 2 and associated references). Moreover, these screens display some variability between approaches, are known to give rise to false negatives, and silencing is less effective in the nervous system. Efficacy can be increased by performing screens in the $r r f-3$ mutant, a strain being hypersensitive to RNAi, likely due to longer half life of RNAi (Simmer et al., 2003). Overall these screens, certainly those by Simmer et al. (2003) and Sonnichsen et al. (2005), indicate that normal larval development depends on functional peroxisomes (Table 2).

In more in depth investigations silencing dsRNAs were injected into the gonads of young adult hermaphrodites, followed by scoring of their effect on the progeny. Rachubinski and coworkers found that RNAi inactivation of Pex5, Pex12, Pex13, and Pex19 greatly reduced the percentage of adult progeny, at 3 days following injection of dsRNA, most progeny being developmentally delayed and still at the L1, L2, or L3 larval stage (Petriv et al., 2002). Targeting of Pex6, Pex1, or Pex2 was without effect, but the employed dsRNAs did also not affect the peroxisomal import of a fluorescent PTS1protein (CFP-SKL). In contrast, injection of dsRNA targeting Pex5, Pex13, or Pex19, caused a cytosolic fluorescence of the reporter. Silencing of Pex12 resulted in fewer but larger peroxisomes.

Thieringer et al. (2003) reported similar experiments. Blocking either Pex5, Pex6, Pex12, Pex13, or Pex19 caused an arrest of the growth of their progeny at the L1 larval stage (Figure 5A). The arrested worms were viable, and resumed growth after 2-8 days, likely depending on quantity and stability of injected DNA, and developed into normal worms.

Development seems less dependent on Pex10. During an ethyl methanesulfonate mutagenesis screen for genes affecting lipid droplets, Zhang et al. (2012) could classify surviving mutants having enlarged lipid droplets into four complementation groups,

${ }^{3}$ In contrast to most other higher eukaryotes, the two catalytic domains of
MFP2 are expressed as separate proteins in C. elegans (Huyghe et al., 2006a). one group being linked to Pex10. In the mutant strain (prx10(hj21)), PTS1 import was affected. Although not discussed in their paper, development and morphology of the worm appeared normal (based on pictures of 1 day adult). Given that the three other groups were linked to peroxisomal $\beta$-oxidation enzymes (maoc-1, dhs-28, daf-22, respectively, corresponding to an enoylCoA hydratase, 3-hydroxyacyl-CoA dehydrogenase and SCP2containing thiolase), one could wonder why only one peroxin was hit in this screen or whether the others remained undetected due to lethality or slower development.

The mechanism underlying the developmental problems was not addressed, but might indeed be caused by peroxisomal metabolic inactivity. Pex5(RNAi) prevents initiation of postembryonic cell divisions, and normal cell migrations including those of neuronal cells, are blocked (Thieringer et al., 2003). This phenotype resembles that of starved larvae, therefore division might require a peroxisomal metabolite. Furthermore, larval development of nematodes seems to be dependent on etherlipid synthesis. Eight days after injecting gonads of adults with dsRNA directed toward ADHAPS, their offspring was still in the larval stage, whereas those injected with non-specific dsRNA produced mature adults (Motley et al., 2000). Similar findings were reported by Petriv et al. (2002). Also $\beta$-oxidation might play a role in development. Upon silencing of $\Delta 3,5-\Delta 2,4$-dienoylCoA isomerase (encoded by Y25C1A.13), an enzyme required for degradation of polyunsaturated fatty acids, or silencing of the three ABC half-transporters (encoded by T02D1.5, C44B7.9, and C44B7.8), implicated in peroxisomal membrane translocation of fatty acids/acyl-CoAs, a similar phenotype is seen: no adult offspring three days after injection (Petriv et al., 2002). It should be noted, however, that silencing of peroxisomal thiolases, either the classical ones (encoded by T02G5.4 and T02G5.8) or SCP2-containing thiolase (encoded by daf-22), had no effect (Petriv et al., 2002). Also important to mention is that the C. elegans dienoyl-CoA isomerase, thought to be the counterpart of mammalian ECH1 (Petriv et al., 2002), which is targeted to both mitochondria and peroxisomes, does not have a PTS1. This complicates the interpretation of these silencing experiments.

Whereas a defective peroxisome biogenesis affects early larval development, silencing of Pex genes at a later stage seems beneficial. An extended life span, 22.7 days compared to 16.22, was seen upon silencing of Pex5 in L4 larvae in the eri-1(mg366) strain, a strain more sensitive to RNAi (Curran and Ruvkun, 2007). Similarly, Zhou et al. reported a $17 \%$ increase for Pex13 and $8 \%$ for Pex5 (15\% for PMX4, a peroxisomal membrane protein), when silenced in 1 day old adult (Zhou et al., 2012). It is suggested that the longer survival is related to reduced generation of reactive oxygen species (ROS) when peroxisomes are less or not functional (see Fransen et al., 2012). The amount of measurable ROS is lowered in the Pex5, Pex11, or Pex13 silenced animals. Strangely, and in contrast to most other screens, silencing of these peroxins in L1 larvae had no effect, but controls on RNAi efficacy are missing.

Summarizing, RNAi based data suggest that peroxins play a critical role in nematode development, but are less important in the adult stage. A drawback of this technique is, however, the 


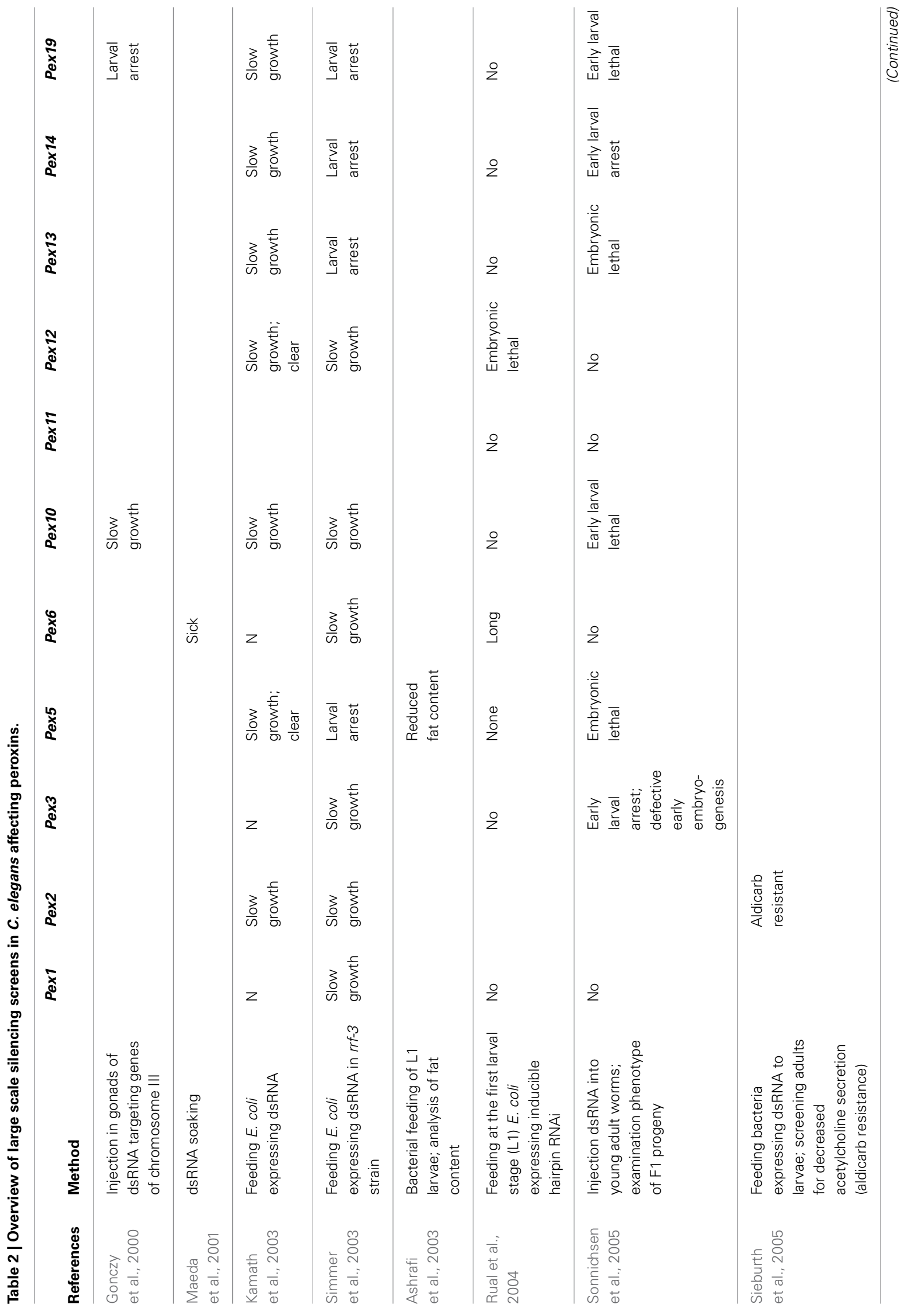




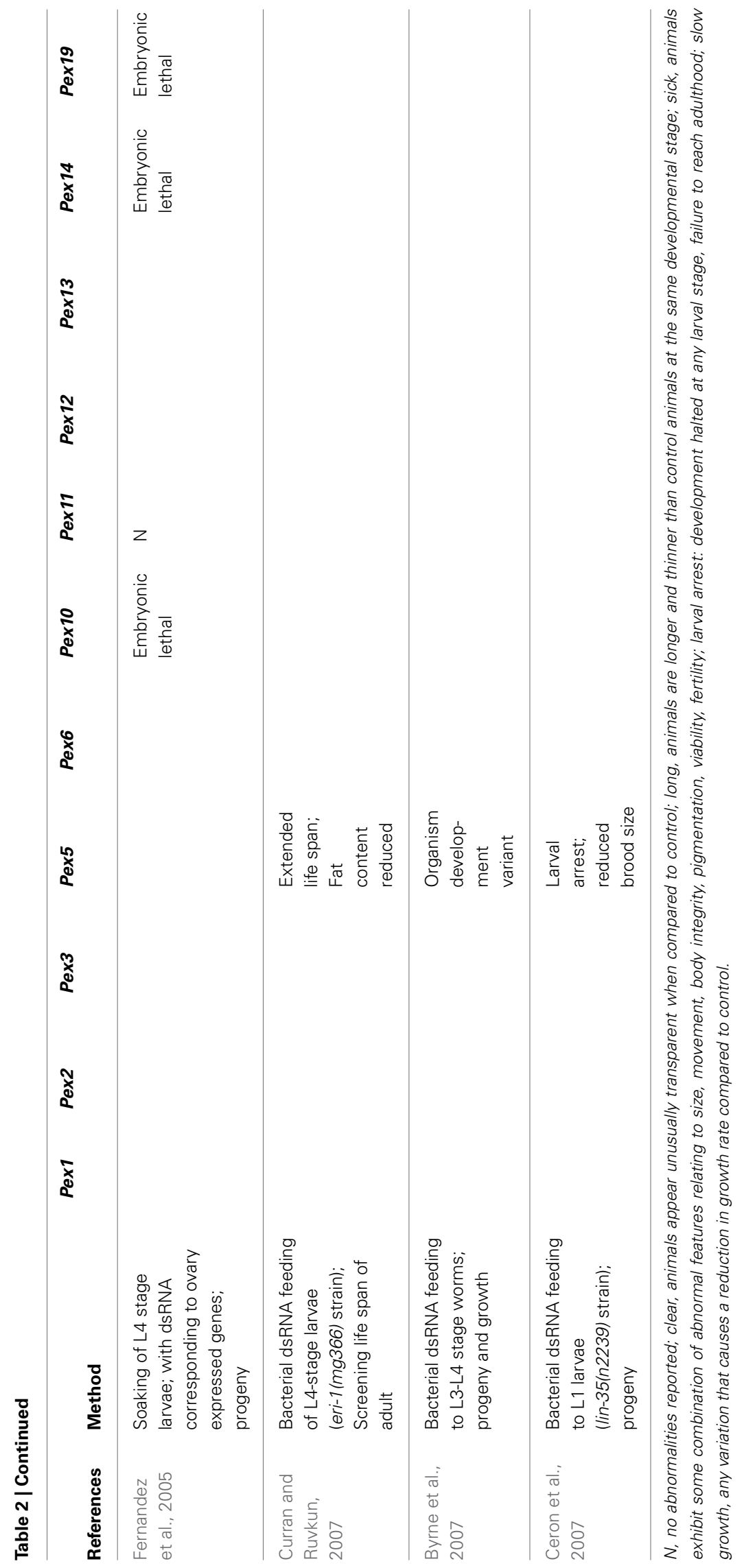



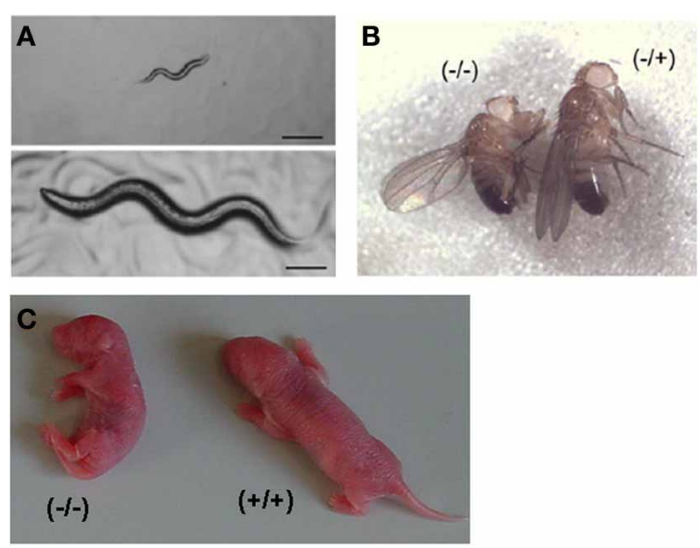

FIGURE 5 | Developmental delay in peroxisome deficient animals. (A) Developmental arrest of $C$. elegans at the L1/L2 stage by Pex5 RNAi (top panel), compared to wild type nematode (bottom panel), being photographed 3 days after being laid. Bar, $10 \mu \mathrm{m}$. Reproduced/adapted with permission from Thieringer et al. (2003). (B) Reduced body size and weight of an adult male homozygous pex $16^{1}$ fruitfly compared to heterozygous animal. Taken from Nakayama et al. (2011). (C) Appearance of newborn mice pups, showing severe hypotonia and growth delay in a Pex $5^{-/-}$pup compared to a wild type littermate.

variability. In the near future, more solid data on the role of peroxins in nematodes are expected, given the increasing availability of deletion mutants (C.elegans mutation consortium. 2012): a Pex5 mutant (tm4948) with a 439 bp deletion is sterile ${ }^{4}$; a Pex1 mutant (tm0392) with a 681 bp deletion is classified as lethal or sterile $^{5}$.

\section{FRUITFLY}

About 21-22 h after fertilization (hpf), Drosophila larvae will hatch from the eggs. One distinguishes 17 steps during this period, known as Bownes stage numbers. In stage 6 (180-195 min), gastrulation starts, whereas formation of the Malphigian tubes (counterpart of kidney in mammals) starts in stage 10 . In the late stage 11 , the stomatogastric nervous system develops. During the subsequent larval stages, three in total, most of the organs/structures of the adult fly will develop, starting from imaginal discs. At the end of the third larval stage (120 hpf), metamorphosis starts, divided in a prepupal period and a pupal period, in total 4 days. Finally, the flies emerge from the pupal case (eclosion). They start mating $12 \mathrm{~h}$ after emergence and will live for about a month.

Based on fatty acid analysis of certain Pex mutants, very long chain fatty acids (VLCFA) are degraded via peroxisomal $\beta$-oxidation in fruitflies (Chen et al., 2010). Related to purine/xanthine metabolism, it should be noted that the eye pigment formation is dependent on peroxisomes. The rosy-506 eye-color mutant lacks xanthine dehydrogenase/oxidase, which is targeted to peroxisomes (Beard and Holtzman, 1987).

\footnotetext{
${ }^{4}$ http://www.shigen.nig.ac.jp/c.elegans/mutants/DetailsSearch? lang=english\&seq $=4948$.

${ }^{5}$ http://www.shigen.nig.ac.jp/c.elegans/mutants/DetailsSearch? lang=english\&seq $=392$.
}

The genome of Drosophila encodes at least 15 peroxins (Chen et al., 2010; Mast et al., 2011), being homologous to mammalian peroxins. Whether orthologous of the fungal Pex20 and Pex23 are expressed (Mast et al., 2011), is questionable (see comments to the related entries in Table 1 ).

Based on RNAi in Drosophila S2 cells expressing GFP-SKL, silencing of Pex1, Pex5, Pex13, Pex16 results in import deficiency, silencing of Pex2, Pex3, Pex6, Pex12, Pex14 in impaired import. Interfering with Pex11 or Pex19 affects peroxisome number (reduced) and size (larger), whereas RNAi of the putative Pex20 or Pex23 has an opposite effect, more peroxisomes of smaller size (Mast et al., 2011).

Although for most of these peroxins, mutants with transposon P1-insertions were present in the repositories (see Table 3), these were not studied in depth. According to Spradling et al. (Spradling et al., 1999), the Pex $2^{f 018}$ allele was lethal, but this was later shown to be due to a second mutation (Chen et al., 2010). More recently, a library of RNAi transgenes, expressing inverted repeats causing conditional gene inactivation, became available, covering $88 \%$ of the predicted protein coding genes (Dietzl et al., 2007). For all fly peroxins, transgenic lines are available (unpublished data), but as far as known, not evaluated.

Related to fly development, and as far as studied in detail, PEX1, PEX3, and PEX13 appear critical. P-element insertion in Pex1 (pex1 ${ }^{\text {s4868 }}$ ) (Chen et al., 2010; Mast et al., 2011) or in Pex13 $\left(\right.$ pex $13^{K G 04339}$ ) (Chen et al., 2010), X-ray mutagenized Pex1 ${ }^{1}$ (Mast et al., 2011) or a deletion in Pex3, generated by P-element imprecise excision of pex3 ${ }^{C 66859}$ (Nakayama et al., 2011), are lethal ${ }^{6}$ at the larval stage when homozygous. Expression of a wild type PEX1 rescues the pex $1^{s 4868}$ or pex $1^{1}$ mutants to survive past the second larval instar (Mast et al., 2011). Pex1 mutant larvae displayed a delay in development, little coordinated locomotion, poor feeding, and died at the L1-L2 stage (Mast et al., 2011). Some larvae even died a few hours after hatching, being unable to crawl out of the eggshells. In the peripheral and central nervous system various abnormalities were documented. These include malformation of the ventral nerve cord (lack of or underdeveloped commissures, breaks in longitudinal connectivities), reduced number of motor neurons, disorganization of glia cells, loss and hypoplasia of peripheral neurons, malformation of eye discs. In the malphigian tubules, structural abnormalities were noticed.

A dsRNA screen was conducted in preblastoderm embryos to detect genes that affect embryonic nervous system development. Although $50 \%$ of the Drosophila genes were covered, only one peroxin was hit, i.e., PEX19. Silencing of Pex19 resulted in disruption of the ventral nerve cord, misrouting of axons and disorganization of dorsal clusters of cells in the peripheral nervous system in stage 15-16 embryos (Koizumi et al., 2007).

Flies with insertional mutations in $\operatorname{Pex} 2\left(p e x 2^{f 0189}\right.$ and pex2 $\left.{ }^{H P 35039}\right)$ (Chen et al., 2010), Pex12 (pex12f01300) (Chen et al., 2010), Pex1 (pex1 ${ }^{\text {S4868}}$ ) (Zhou et al., 2012) or Pex13 $\left(\right.$ pex $\left.13^{K G 04339}\right)$ (Zhou et al., 2012) or a deletion in Pex10 (excision

\footnotetext{
${ }^{6}$ The Pex1 $1^{S 084807}$ and $P e x 1^{02402}$ alleles were reported to be semi-lethal and in homozygous third instar larvae necrosis was observed in salivary gland cells (Burmester et al., 2000).
} 
Table 3 | Overview of classical peroxin alleles in Drosophila melanogaster.

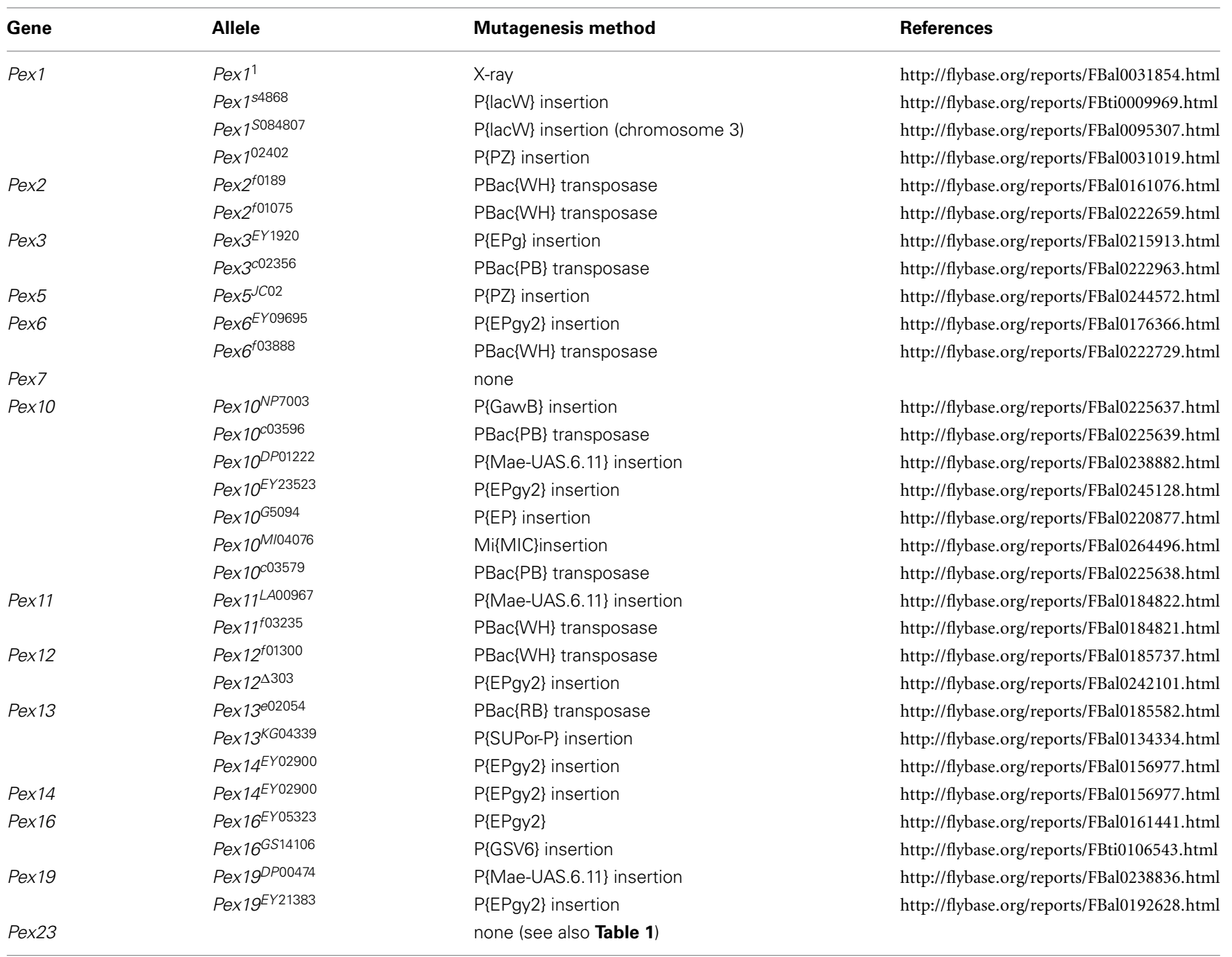

of P-element in pex10 ${ }^{\text {EY23523 }}$ ) (Chen et al., 2010) or Pex16 (excision of pex16 ${ }^{\text {CG3947 }}$ ) (Nakayama et al., 2011) are viable. Fertility, however, was reduced in Pex2, Pex10, or Pex12 female mutants and males were sterile (Chen et al., 2010). The latter phenotype was due to an arrest in the germ cell development at the level of the spermatocyte growth stage. Similarly, male fertility was compromised in the Pex16 mutant (Nakayama et al., 2011). Testes of this mutant were smaller and did not contain mature sperm cells, although early spermatocyte cysts were still present, due to an arrest in the maturation of spermatocytes at the young apolar stage (Figures 6A,B). This arrest and the fertility could be rescued by overexpression of PEX16 in the cyst cells, although germ cells still lacked peroxisomes. Expression of PEX16 in the germline cells, however, did not rescue the spermatogenesis, indicating that peroxisomes in the somatic cysts cells play an important role in spermatogenesis (Nakayama et al., 2011). This is, however, in contrast to the Pex 2 mutant in which rescue of the germ cells normalized the phenotype (Chen et al., 2010). It is suggested that VLCFA, which show an age-dependent increase in Pex10 mutants
(2.9- and 3.9-fold for whole body $\mathrm{C}_{26: 0}$ at 2 and 15 days, respectively), play a critical role in spermatogenesis in insects (Chen et al., 2010).

Although viable, the Pex16 mutant adult flies were considerably smaller (30\% females; 15\% males) (Figure 5B) and their locomotion was affected, the latter likely being responsible for a severe reduction of their lifespan (to one third for females; to one-fourth for males) (Nakayama et al., 2011). Peroxisomes were still present in the malpighian tubule cells of Pex16 mutant flies, but their number is greatly reduced. Not unexpectedly, the eye pigmentation was affected in Pex16 mutants, resembling the rosy phenotype, and biochemically, an increase in (whole body) VLCFA levels was seen (2-fold for $\mathrm{C}_{24: 0}$ in males, 3-fold in females). Histology of brain revealed a low density of dendritic trees in the lobula plate of the optic lobe; other cells in the optic lobe and other parts of the brain were unaffected. The dendritic reduction was already visible at the pupal stage and did not aggravate with age, suggesting a developmental problem, not a degeneration. Interestingly this defect can be rescued by 


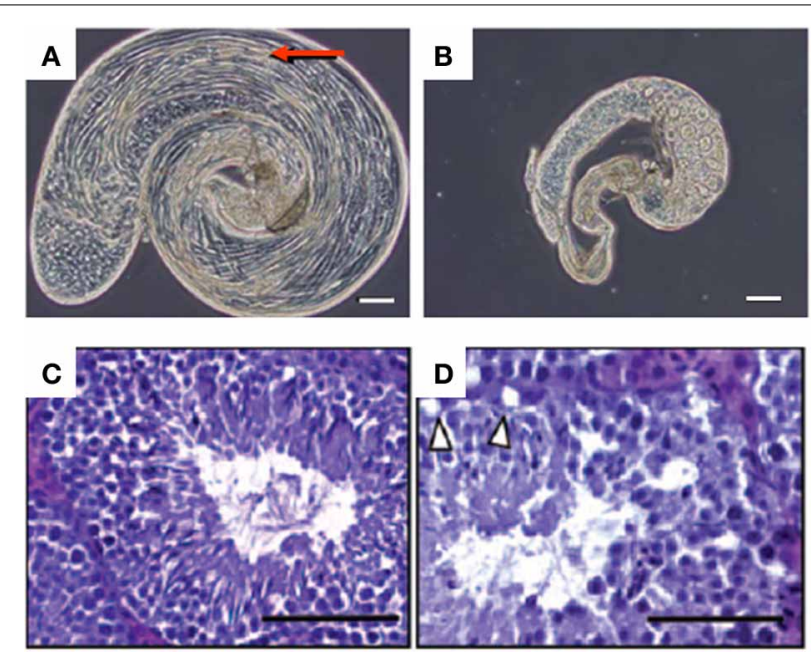

FIGURE 6 | Male fertility problems in peroxisome deficient animals. (A,B) Phase-contrast micrographs of testes of fruitflies, with bundles of elongated spermatids (arrow) in a wild type (A) and arrest of germline cell maturation in a pex $16^{1}$ homozygous fruitfly (B). Bar, $100 \mu \mathrm{m}$. Taken from Nakayama et al. (2011). (C,D) Hematoxylin-eosin staining of 7 weeks old testis of wild type (C) and Sertoli PEX5 knockout mice (D), the latter showing lipid droplets that were emptied during the embedding procedure in the outer layer of the seminiferous epithelium (arrowheads) and reduced numbers of spermatozoa in the lumen of the tubuli. Bar $100 \mu \mathrm{m}$. Taken from Huyghe et al. (2006b).

expression of PEX16 in the fat body or in differentiated neurons (Nakayama et al., 2011).

The viability of the above mentioned Pex1 and Pex13 mutants can be explained by the nature of the mutation, affecting the promoter and resulting in lower expression $(\sim 20 \%$ of wild type $)$ (Zhou et al., 2012). Interestingly, life span of these flies increased ( $16 \%$ in males; $13 \%$ in females), whereas their hydrogen peroxide levels were decreased. This is similar to findings reported in nematodes (see Nematodes). Along the same lines, Pex19 expression was reported to be repressed (1.8-fold) when feeding flies 4-phenylbutyrate, a diet which extends their lifespan by $36 \%$ (Kang et al., 2002). The latter compound is known in the peroxisomal field by its ability to induce the expression of ABCD2 (Kemp et al., 1998), an ABC-transporter functionally related to $\mathrm{ABCD} 1$ which is mutated in X-ALD.

\section{ZEBRAFISH}

Given the translucency of the embryo and the short developmental period, zebrafish (Danio rerio) is an organism of choice for dynamic developmental studies. Gastrulation starts around $6 \mathrm{~h}$ post-fertilization (hpf), first somites are formed at $11 \mathrm{hpf}$, and at $24 \mathrm{hpf}$ the embryo, surrounding the yolk sac, shows already the typical fish-like shape and tail and primary organs have been formed. In the subsequent day, the circulatory system and fins are formed. Cartilage development starts at $48 \mathrm{hpf}$, and at 3 days, fishes are self-supporting, first as larvae till 1 month of age, then juveniles till adulthood, around 90 days. Total life span is around 2 years.
Transcripts for peroxisomal matrix and membrane proteins can be detected starting at $24 \mathrm{hpf}$ in the head region, whereas catalase-positive peroxisomes become visible in the liver and the pronephric duct in 4 days old fishes (Krysko et al., 2010). In adult fish, peroxisomes are most prominent in liver (Braunbeck et al., 1990; Krysko et al., 2010), renal proximal tubules (Krysko et al., 2010) and the intestinal epithelium (Krysko et al., 2010). For more information on expression in zebrafish during embryogenesis, the reader is referred to a large scale in situ hybridization screen (Thisse et al., 2004).

Similarly to rodents, zebrafish hepatic peroxisomes respond to peroxisome proliferators and an increased number is observed in liver when fishes are exposed to clofibrate (Venkatachalam et al., 2012) or phthalate esters (Ortiz-Zarragoitia et al., 2006).

Based on scattered information, the organelles are active in $\beta$ oxidation. Presence of ACOX1 was demonstrated (Ibabe et al., 2005; Morais et al., 2007) and the enzymes able to act on branched fatty acids, such as MFP2 (encoded by hsd17b4) and SCPX (encoded by $s c p 2 a$ ), are expressed (Thisse et al., 2004), but apparently $\mathrm{C}_{24}$-bile acids are not formed in zebrafish, in contrast to other teleost fish (Hofmann et al., 2010). Based on genomic information, fish peroxisomes can synthesize etherlipids and contain an $\alpha$-oxidation pathway.

Regarding peroxisome biogenesis, all classical peroxins are expressed in D. rerio (see Table 1), and based on high throughput analysis, Pex3, Pex5, Pex7, Pex10, Pex14, Pex19 are ubiquitously expressed from $24 \mathrm{hpf}$ on, with higher expression in the head region (Thisse et al., 2004).

Despite the wide spread use of morpholinos to interfere with expression in zebrafish, in only few reports, as far as documented, this technique was applied to peroxisome biogenesis. Injection of morpholinos, intended to block the splice sites in Pex3 or Pex13, into one-cell embryos did not affect peroxisomal import. Subsequent RNA analysis revealed that these morphilinos did not eliminate exons, instead produced a short in frame insertion (Pex3) or deletion (Pex13) (Krysko et al., 2010). Blocking of the translation of Pex13 was more effective to reduce the number of hepatic peroxisomes, but high doses were needed and not all of the injected embryos showed such response. A Pex5 blocking morpholino had no effect at low dose, and caused embryonal death at higher dose. Finally, overexpression via mRNA injection of an $\mathrm{N}$-terminal domain of (human) PEX3, having a dominant negative effect in human fibroblasts (Soukupova et al., 1999), did not affect biogenesis (Krysko et al., 2010). Coutinho et al. (2004) did not observe any abnormalities at $32 \mathrm{hpf}$ when one cell stage embryos were injected with morpholinos directed against the $5^{\prime}$ end of Pex19 (notochord differentiation or pigmentation were normal), the efficacy of the morpholino was, however, not controlled.

Although technically easy, the dilution of morpholinos or mRNA upon subsequent cell divisions, combined with the turnover of peroxisomes, half life estimated at 2 days in cultured mammalian cells (Huybrechts et al., 2009), is a major obstacle in the embryonic injection approach. In the near future, more solid data might emerge from analysis of insertional zebrafish mutants. 
Although tools to carry out large scale insertional mutagenesis and positional cloning in zebrafish were developed several years ago using mouse retroviral vectors (Gaiano et al., 1996; Golling et al., 2002) the number of created, annotated and available mutants, however, remains low. For a more targeted approach, engineered $\mathrm{Zn}$-finger nucleases are a promising tool to create zebrafish knockouts (Foley et al., 2009).

\section{MICE}

The intra-uterine development of mice takes 20-21 days. During this period, embryos are depending on the maternal circulation with regards to most nutrients. Examples of exceptions are brain poly-unsaturated fatty acids (PUFA) that are partly dependent on local synthesis (Janssen et al., 2000). At birth, organogenesis of most organs has been completed, except formation of the cerebellum which extends into the postnatal period and maturation of gonads before adulthood. After birth, pups are nursed and milk-fed till weaning, about 3 weeks later. At 6 weeks (females) or eight (males) of age, animals become sexually active and start to breed. Lifespan, under laboratory conditions, is 18-30 months.

In mammals, peroxisomal $\beta$-oxidation serves to generate PUFA and $\mathrm{C}_{24}$ bile acids. The first are implicated in many brain processes such as learning, memory, behavior; the latter are required for efficient uptake of lipophilic nutrients in the intestines. This pathway also shortens VLCFA, pristanic acid and dicarboxylic fatty acids (Van Veldhoven, 2010). Removal of the toxic phytanic acid requires an active $\alpha$-oxidation. Plasmalogen deficiency in mammals is linked to a specific bone developmental problem, in man known as rhizomelic chondrodysplasia punctata (RCDP), and RCDP type I is linked to PEX7 deficiency.

Currently, the following peroxins have been inactivated in mice: PEX5 (Baes et al., 1997), PEX2 (Faust and Hatten, 1997), PEX11A (Li et al., 2002a; Weng et al., 2013), PEX11B (Li et al., 2002b), PEX13 (Maxwell et al., 2003), and PEX7 (Brites et al., 2003; Braverman et al., 2010). Mice lacking both PEX11A and PEX11B were also created (Li et al., 2002b), or lacking a peroxin together with another peroxisomal protein such as Pex7 $7^{-/-}:$Abcd $1^{-/-}$mice (Brites et al., 2009).

Given obvious similarities, PEX5, PEX2, and PEX13 deficiencies can be treated together, separately from the PEX7 knockout model. Considering that PEX11 proteins are not involved in peroxisome biogenesis per se and that this process is not affected in the Pex $11 a^{-/-}$and Pex $11 b^{-/-}$mice, but mainly their elongation and abundance, these models will not be discussed further in this chapter. Below we will summarize the main findings in the other mouse models [see also recent reviews by Baes and Van Veldhoven (2006, 2012)].

Related to PEX5, PEX2, and PEX13 deficient models, knockouts pups are born alive in the expected Mendelian ratio and without major deformities or skeletal malformations, suggesting a normal intra-uterine development (Baes et al., 1997; Maxwell et al., 2003). However, in case of PEX2 deficiency in an inbred 129 background, embryonic lethality was reported and only $20 \%$ of the pups are born (Faust and Hatten, 1997). In these three models, newborn pups are, however, growth retarded and severely hypotonic (Figure 5C), hence they do not feed and die 6-24h after birth. Some Pex2 $2^{-/-}$pups (20-30\%), in a mixed Swiss Webster $\times 129$ SvEv background, survive for about 1-2 weeks (Faust and Hatten, 1997) and the postnatal survival can be improved by oral bile acid therapy ( $9 \%$ alive after 30 days) (Keane et al., 2007). The reason for this strain-dependent differences, although often seen in other mouse models, is not clear.

At closer inspection, there are some developmental problems, especially in the brain. Lamination of the cerebral cortex is affected due abnormal and delayed neuron migration (Baes et al., 1997; Faust and Hatten, 1997; Gressens et al., 2000). In the longer surviving Pex2 $2^{-/-}$pups, dendritic arborization of the Purkinje cells in the cerebellum is reduced and their axons are dystrophic (Faust, 2003). Similar findings were seen in a Pex5 and Pex13 brain knockout (see further).

Finally, at the subcellular level, mitochondrial abnormalities were documented in liver (Baumgart et al., 2001; Keane et al., 2007) and lamellar lipid deposits were evident in the adrenocortical cells (Faust and Hatten, 1997).

Biochemically, various peroxisome dependent parameters are abnormal in pups with these Pex gene inactivations [accumulation of VLCFA, lack of plasmalogen, abnormal bile acids, shortage of docosahexaenoic acid (DHA)]. Changes in brain PUFA composition have been proposed to modify $\alpha$-synuclein (Yakunin et al., 2010), which could contribute to the neuropathology. In whole brain extracts of these three models, Yakunin et al. (2010) showed increasing oligomerization and phosphorylation of $\alpha$-synuclein. Such changes trigger intraneuronal deposition of $\alpha$-synuclein (Lewy bodies), being a hallmark of synucleopathies such as Parkinson disease.

A different phenotype is seen in PEX7 deficient mice (Brites et al., 2003). Embryonic lethality is not seen, but these pups are also hypotonic and growth impaired (15-30\% lower body weight at birth), and the majority (70\%) dies before weaning (50\% after 1 day, likely due to the hypotonia). The surviving animals do live till adulthood and longer, but males are infertile, the seminiferous epithelium being devoid of spermatogonia and spermatocytes. In brain, a delay in neuronal migration is seen, and ossification of distal bone elements of the limbs, skull and vertebrae, is defective. The amount of white, but not brown, adipose tissue is reduced (Brites et al., 2011). Bilateral cataracts develop 2 weeks after birth (Brites et al., 2011), the time pups open their eye lids. Biochemically, plasmalogens are depleted, phytanic acid cannot be degraded, and VLCFA oxidation is impaired in fibroblasts, but increased VLCFA levels are only found in spleen, spinal cord and neonatal brain (Brites et al., 2009).

In Pex7 hypomorphic mice, in which Pex7 transcripts are reduced to $5 \%$, lifespan is normal (Braverman et al., 2010). The mice are still smaller, but are fertile. Their tissue content of plasmalogens is low but not absent, DHA in $\mathrm{RBC}$ is lowered and phytanic acid accumulates. Pathological findings include endochondral ossification defects, abnormalities in lens fibers and eye cataract (Braverman et al., 2010).

Feeding 6-weeks old $P e x 7^{-/-}$mice with 1-Ooctadecylglycerol, an etherlipid which is bypassing the 
peroxisomal biosynthetic steps (see Figure 3), reveals that several phenotypic abnormalities are related to plasmalogen deficiency. The diet restores plasmalogen levels in non-nervous tissues. In parallel, testicular pathology is ameliorated (spermatogenesis was restored, although mature spermatozoa were still not detectable), and adipocytes displayed a normal size and fat content. When giving 1-O-octadecylglycerol to newborn pups, via supplementing it to the diet of the mother, testicular degeneration was prevented and cataract formation was absent or only unilateral and reduced to a small nuclear cataract (Brites et al., 2011). In the hypomorphic Pex $7^{-/-}$mice, such treatment did not affect the cataracts (Braverman et al., 2010).

Severe bone abnormalities, a major hallmark in patients with PEX7 deficiency as reflected in their name (RCDP), are not observed in mice. Upon closer investigation, a delay, however, in endochondral bone formation was reported in both complete (Brites et al., 2003) and hypomorphic PEX7 (Braverman et al., 2010) deficient mice, likely due to a delayed maturation of chondrocytes at the pre-hypertrophic state, but further mechanistic insights were not generated.

Given the lethality of peroxin knockouts, especially of those with affected PTS1-import, developmental and behavioral studies are limited. This can be circumvented by conditional knock-out whereby peroxisomes are removed in specific tissues and/or at a certain stage. Tissue-specific removal of peroxisomes can be established by crossing mice containing a floxed Pex gene (Baes et al., 2002) with mice expressing cre in a promoter-specific manner. The promoter also determines the time point from when on the Pex gene is irreversibly inactivated in the targeted cells and their descendents. This technology was applied for Pex5 creating mice lacking peroxisomes in the central nervous system (CNS) [nestin-Cre, in neural precursors from embryonic (E) day 11 (Hulshagen et al., 2008)], hepatocytes [alfafoetoprotein-Cre, from E10 (Krysko et al., 2007) and albumin-Cre, from birth (Peeters et al., 2011)]. By using a similar approach, brain specific PEX13 knockouts were obtained (nestin-Cre) (Müller et al., 2011).

Pex5 was further inactivated in specific cell types by using appropriate Cre-expressing mice: Sertoli cells (Amh-Cre, from E14) (Huyghe et al., 2006b), oligodendrocytes (Cnp-Cre, from E14) (Kassmann et al., 2007), principal neurons in the forebrain (Nex-Cre, from E12) (Bottelbergs et al., 2010), and astrocytes (Gfap-Cre from E13) (Bottelbergs et al., 2010). The specific inactivation of PEX5 in adipocytes failed due to the non-selectivity of the $a P 2$ promoter driving Cre expression (Martens et al., 2012).

Overall, these studies indicate that absence of peroxisomes in adipose (Martens et al., 2012), neurons (Bottelbergs et al., 2010), astrocytes (Bottelbergs et al., 2010), or Sertoli cells (Huyghe et al., 2006b) does not compromise life span. Postnatal thriving, however, requires functional liver and brain peroxisomes. Moreover, absence in liver results in life threatening development of hepatocarcinomas (Dirkx et al., 2005), absence in brain shortens life span considerably to 6 months with $20 \%$ dead before 3 weeks for Pex5-loxP:nestin-cre (Hulshagen et al., 2008) or 35 days for Pex13-loxP:nestin-cre (Müller et al., 2011) mice. Of the different models with specific brain cell inactivation, the oligodendrocyte knockout represents the worst outcome: almost none of the affected animals survive 1 year of age (Kassmann et al., 2007). Its phenotype resembles that of a total deficiency of peroxisomes in the brain, but with delayed onset of demyelination, axonal loss and neuroinflammation. The latter encompasses a strong activation of the innate immune system with microglia reactivity and increased expression of pro-inflammatory markers (Kassmann et al., 2007; Bottelbergs et al., 2012). The biochemical factor(s) contributing to or causing this phenotype remain unclear. To which extent peroxisomal metabolites can be transferred from one cell type to another in brain, or from the body to the brain, is not fully established, but an important role of peroxisomes in neurons or astrocytes in pre- and postnatal life can be excluded.

For more information about these models, and how peroxin deficiencies affect brain, liver and testis, we refer to recent reviews (Baes and Van Veldhoven, 2006, 2012; Baes and Aubourg, 2009). It should be stressed that part of the pathology seen in these mouse models might be related to the, not yet completely understood, interplay between peroxisomes, their metabolites and other organelles. As initially observed in PEX5 (Baumgart et al., 2001) and PEX2 knockouts (Keane et al., 2007), and further documented in the albumin-Cre/Pex5-loxP mice (Dirkx et al., 2005), absence of peroxisomes in hepatocytes affects their mitochondria severely. Structural alterations are seen in the inner mitochondrial membrane, and its potential is collapsed. Activities of complex I, III, and V are reduced. In addition, lipid droplets and ER stress are noticed. Based on the upregulation of ATF3, ATF4, ATF6, and CHOP, the unfolded protein response pathway is activated in absence of peroxisomes (Dirkx et al., 2005). Similar findings were seen in liver of surviving PEX2 pups, the integrated stress response mediated by PERK and ATF4 signaling being activated (Kovacs et al., 2009). It is postulated that perturbed peroxisomal $\beta$-oxidation metabolites (e.g., bile acid (intermediates), dicarboxylic acids), are causative factors given the fact that ER stress is also seen in mice with $\beta$-oxidation defects (Huang et al., 2011).

\section{CONCLUSION}

Although peroxisomes are not essential for cell functioning and survival, at the multicellular level they are indispensable as demonstrated by the different animal models treated in this chapter.

A common feature in animals with peroxisome biogenesis defects is a developmental delay, smaller size at hatching/birth and limited to very short lifespan (Figure 5). The reason for the delay is not clear. In most models, organogenesis seems to proceed normal, but the central nervous system appears sensitive to absence of peroxisomes (abnormal cerebellar lamination and delayed neuron migration in mice; malformation of the ventral nerve cord in fruitfly; block of neuron cell migration in L1 stage in nematodes). In a later stage of life, neuronal problems are manifested in reduced locomotion (larvae of insects) or coordination and motor skills (mice). In nematodes, normal larval development is dependent on ether lipids. In mice (and man), plasmalogen deficiency is compatible with prenatal 
development but the newborns exhibit already several abnormalities.

With regard to the nervous system, an intriguing question is to which extent myelinization/demyelinization and axonal integrity are linked to peroxisomes. Myelin, formed by the oligodendrocytes, is indeed enriched in metabolites related to peroxisomes (plasmalogens, VLCFA). It is therefore surprising that myelination is initially normal when peroxisomes are ablated from oligodendroglia and that in adulthood myelin becomes destabilized. Importantly, as both in the total brain and the oligodendrocyte knockout, degenerated axons are observed surrounded with a normal myelin sheet, it was postulated that oligodendroglial peroxisomes serve to support axons independent of myelination. This is further endorsed by the finding that peroxisomes are abundant in paranodes (Kassmann et al., 2011), sites where glia and axons interact. In this context, one should recall that in species in which axons are not myelinated such as fruitfly, neuronal abnormalities are seen when peroxisomes are ablated (Nakayama et al., 2011).

Another remarkable finding, although not studied in all models, is the male sterility, documented at least in Drosophila and in mice knockouts (Figure 6). In fly, peroxisomes of the cysts cell appear to be important for spermatogenesis (Nakayama et al., 2011), which is mirrored in mice where peroxisomes are necessary in the Sertoli cells (Huyghe et al., 2006b). In insects, the infertility was linked to accumulation of VLCFA, in mice experimental evidence points toward both an accumulation of VLCFA and VLCFA-PUFA (Huyghe et al., 2006b). The importance of normal peroxisomal $\beta$-oxidation for male fertility was further confirmed in ACOX1 (Fan et al., 1996) and MFP2 knockout mice (Huyghe et al., 2006b). In addition, a depletion of ether lipids also causes male infertility in PEX7 (Brites et al., 2011) and GNPAT (Rodemer et al., 2003) knockout mice.

Finally, related to aging and neurodegenerative diseases, and the emerging role of peroxisomes in ROS signaling (Titorenko and Terlecky, 2011; Fransen et al., 2012) scattered information derived from the animal models discussed above, suggest that less active peroxisomes in adulthood could positively contribute to longevity. This seems, however, in conflict with the general concept that the metabolic activity of these organelles becomes compromised during aging. On the other hand, it would be consistent with studies on the importance of catalase in aging. Improving the removal of peroxide in peroxisomes, by expressing an engineered catalase with a higher affinity for PEX5, delays the appearance of senescence markers in human fibroblasts (Koepke et al., 2007). Hence, not the peroxisomal metabolic activity, but the ratio of ROSgeneration/removal (Fransen et al., 2013), might be a determining factor in aging.

\section{ACKNOWLEDGMENTS}

Research by the authors is supported by grants from the Fonds voor Wetenschappelijk Vlaanderen (FWO) (G.0760.09 and G.0675.12 to Myriam Baes; G.0721.10N to Paul P. Van Veldhoven) and of the KU Leuven (OT/08/40 and OT12/79 to Myriam Baes; OT/09/045 to Paul P. Van Veldhoven).

\section{REFERENCES}

Ashrafi, K., Chang, F. Y., Watts, J. L., Fraser, A. G., Kamath, R. S., Ahringer, J., et al. (2003). Genome-wide RNAi analysis of Caenorhabditis elegans fat regulatory genes. Nature 421, 268-272. doi: 10.1038/nature01279

Baes, M., and Aubourg, P. (2009). Peroxisomes, myelination, and axonal integrity in the, CNS. Neuroscientist 15, 367-379. doi: 10.1177/1073858409336297

Baes, M., Dewerchin, M., Janssen, A., Collen, D., and Carmeliet, P. (2002). Generation of Pex5-loxP mice allowing the conditional elimination of peroxisomes. Genesis 32, 177-178. doi: 10.1002/gene.10047

Baes, M., Gressens, P., Baumgart, E., Carmeliet, P., Casteels, M., Fransen, M., et al. (1997). A mouse model for Zellweger syndrome. Nat. Genet. 17, 49-57. doi: 10.1038/ng0997-49

Baes, M., and Van Veldhoven, P. P. (2006). Generalised and conditional inactivation of Pex genes in mice. Biochim. Biophys. Acta 1763, 1785-1793. doi: 10.1016/j.bbamcr.2006.08.018

Baes, M., and Van Veldhoven, P. P. (2012). Mouse models for peroxisome biogenesis defects and beta-oxidation enzyme deficiencies. Biochim. Biophys. Acta 1822, 1489-1500. doi: 10.1016/j.bbadis.2012.03.003

Banerjee, S. K., Kessler, P. S., Saveria, T., and Parsons, M. (2005). Identification of trypanosomatid PEX19: functional characterization reveals impact on cell growth and glycosome size and number BANERJEE2005. Mol. Biochem. Parasitol. 142, 47-55. doi: 10.1016/j.molbiopara.2005.03.008

Baumgart, E., Vanhorebeek, I., Grabenbauer, M., Borgers, M., Declercq, P. E., Fahimi, H. D., et al. (2001). Mitochondrial alterations caused by defective peroxisomal biogenesis in a mouse model for Zellweger syndrome (PEX5 knockout mouse). Am. J. Pathol. 159, 1477-1494. doi: 10.1016/S0002-9440(10)62534-5

Beard, M. E., and Holtzman, E. (1987). Peroxisomes in wild-type and rosy mutant Drosophila melanogaster. Proc. Natl. Acad. Sci. U.S.A. 84, 7433-7437. doi: 10.1073/pnas.84.21.7433

Bottelbergs, A., Verheijden, S., Hulshagen, L., Gutmann, D. H., Goebbels, S., Nave, K. A., et al. (2010). Axonal integrity in the absence of functional peroxisomes from projection neurons and astrocytes. Glia 58, 1532-1543. doi: 10.1002/glia.21027

Bottelbergs, A., Verheijden, S., Van Veldhoven, P. P., Just, W., Devos, R., and Baes, M. (2012). Peroxisome deficiency but not the defect in ether lipid synthesis causes activation of the innate immune system and axonal loss in the central nervous system. J. Neuroinflam. 9, 61. doi: 10.1186/1742-2094-9-61

Braunbeck, T., Gorge, G., Storch, V., and Nagel, R. (1990). Hepatic steatosis in zebra fish (Brachydanio rerio) induced by long-term exposure to gamma-hexachlorocyclohexane. Ecotoxicol. Environ. Saf. 19, 355-374. doi: 10.1016/0147-6513(90)90036-5

Braverman, N., Zhang, R., Chen, L., Nimmo, G., Scheper, S., Tran, T., et al. (2010). A Pex7 hypomorphic mouse model for plasmalogen deficiency affecting the lens and skeleton. Mol. Genet. Metab. 99, 408-416. doi: 10.1016/j.ymgme.2009.12.005

Brites, P., Ferreira, A. S., da Silva, T. F., Sousa, V. F., Malheiro, A. R., Duran, M., et al. (2011). Alkyl-glycerol rescues plasmalogen levels and pathology of ether-phospholipid deficient mice. PLOS ONE 6:e28539. doi: 10.1371/journal.pone.0028539

Brites, P., Mooyer, P. A., el Mrabet, L., Waterham, H. R., and Wanders, R. J. (2009). Plasmalogens participate in very-long-chain fatty acid-induced pathology. Brain 132, 482-492. doi: 10.1093/brain/awn295

Brites, P., Motley, A. M., Gressens, P., Mooyer, P. A., Ploegaert, I., Everts, V., et al. (2003). Impaired neuronal migration and endochondral ossification in Pex7 knockout mice: a model for rhizomelic chondrodysplasia punctata. Hum. Mol. Genet. 12, 2255-2267. doi: 10.1093/hmg/ddg236

Brocard, C., and Hartig, A. (2006). Peroxisome targeting signal 1: is it really a simple tripeptide? Biochim. Biophys. Acta 1763, 1565-1573. doi: 10.1016/j.bbamcr.2006.08.022

Burmester, T., Mink, M., Pal, M., Laszloffy, Z., Lepesant, J., and Maroy, P. (2000). Genetic and molecular analysis in the 70CD region of the third chromosome of Drosophila melanogaster. Gene 246, 157-167. doi: 10.1016/S03781119(00)00066-4

Butcher, R. A., Ragains, J. R., Li, W., Ruvkun, G., Clardy, J., and Mak, H. Y. (2009). Biosynthesis of the Caenorhabditis elegans dauer pheromone. Proc. Natl. Acad. Sci. U.S.A. 106, 1875-1879. doi: 10.1073/pnas.0810338106

Byrne, A. B., Weirauch, M. T., Wong, V., Koeva, M., Dixon, S. J., Stuart, J. M., et al. (2007). A global analysis of genetic interactions in Caenorhabditis elegans. $J$. Biol. 6:8. doi: 10.1186/jbiol58 
C.elegans mutation consortium. (2012). Large-scale screening for targeted knockouts in the Caenorhabditis elegans genome. G3 2, 1415-1425. doi: $10.1534 / \mathrm{g} 3.112 .003830$

Ceron, J., Rual, J. F., Chandra, A., Dupuy, D., Vidal, M., and van den Heuvel, S. (2007). Large-scale RNAi screens identify novel genes that interact with the C. elegans retinoblastoma pathway as well as splicing-related components with synMuv B activity. BMC Dev. Biol. 7:30. doi: 10.1186/1471-213X-7-30

Chen, H., Liu, Z., and Huang, X. (2010). Drosophila models of peroxisomal biogenesis disorder: peroxins are required for spermatogenesis and very-long-chain fatty acid metabolism. Hum. Mol. Genet. 19, 494-505. doi: 10.1093/hmg/ddp518

Coutinho, P., Parsons, M. J., Thomas, K. A., Hirst, E. M., Saude, L., Campos, I., et al. (2004). Differential requirements for COPI transport during vertebrate early development. Dev. Cell 7, 547-558. doi: 10.1016/j.devcel.2004.07.020

Cregg, J. M., van der Klei, I. J., Sulter, G. J., Veenhuis, M., and Harder, W. (1990). Peroxisome-deficient mutants of Hansenula polymorpha. Yeast 6, 87-97. doi: 10.1002/yea.320060202

Curran, S. P., and Ruvkun, G. (2007). Lifespan regulation by evolutionarily conserved genes essential for viability. PLoS Genet. 3:e56. doi: 10.1371/journal.pgen.0030056

de Vet, E. C., Prinsen, H. C., and van den Bosch, H. (1998). Nucleotide sequence of a cDNA clone encoding a Caenorhabditis elegans homolog of mammalian alkyl-dihydroxyacetonephosphate synthase: evolutionary switching of peroxisomal targeting signals. Biochem. Biophys. Res. Commun. 242, 277-281. doi: 10.1006/bbrc. 1997.7950

Dietzl, G., Chen, D., Schnorrer, F., Su, K. C., Barinova, Y., Fellner, M., et al. (2007). A genome-wide transgenic RNAi library for conditional gene inactivation in Drosophila. Nature 448, 151-156. doi: 10.1038/nature05954

Dirkx, R., Vanhorebeek, I., Martens, K., Schad, A., Grabenbauer, M., Fahimi, D., et al. (2005). Absence of peroxisomes in mouse hepatocytes causes mitochondrial and ER abnormalities. Hepatology 41, 868-878. doi: 10.1002/hep. 20628

Distel, B., Erdmann, R., Gould, S. J., Blobel, G., Crane, D. I., Cregg, J. M., et al. (1996). A unified nomenclature for peroxisome biogenesis factors. J. Cell Biol. 135, 1-3. doi: 10.1083/jcb.135.1.1

Dodt, G., Warren, D., Becker, E., Rehling, P., and Gould, S. J. (2001). Domain mapping of human PEX5 reveals functional and structural similarities to Saccharomyces cerevisiae Pex18p and Pex21p. J. Biol. Chem. 276, 41769-41781. doi: 10.1074/jbc.M106932200

Erdmann, R., Veenhuis, M., Mertens, D., and Kunau, W. H. (1989). Isolation of peroxisome-deficient mutants of Saccharomyces cerevisiae. Proc. Natl. Acad. Sci. U.S.A. 86, 5419-5423. doi: 10.1073/pnas.86.14.5419

Escano, C. S., Juvvadi, P. R., Jin, F. J., Takahashi, T., Koyama, Y., Yamashita, S., et al. (2009). Disruption of the Aopex11-1 gene involved in peroxisome proliferation leads to impaired Woronin body formation in Aspergillus oryzae. Eukaryotic Cell 8, 296-305. doi: 10.1128/EC.00197-08

Fan, C. Y., Pan, J., Chu, R., Lee, D., Kluckman, K. D., Usuda, N., et al. (1996). Hepatocellular and hepatic peroxisomal alterations in mice with a disrupted peroxisomal fatty acyl-coenzyme A oxidase gene. J. Biol. Chem. 271, 24698-24710. doi: 10.1074/jbc.271.40.24698

Fan, J., Quan, S., Orth, T., Awai, C., Chory, J., and Hu, J. (2005). The Arabidopsis PEX12 gene is required for peroxisome biogenesis and is essential for development. Plant Physiol. 139, 231-239. doi: 10.1104/pp.105.066811

Faust, J. E., Verma, A., Peng, C., and McNew, J. A. (2012). An inventory of peroxisomal proteins and pathways in Drosophila melanogaster. Traffic 13, 1378-1392. doi: 10.1111/j.1600-0854.2012.01393.x

Faust, P. L. (2003). Abnormal cerebellar histogenesis in PEX2 Zellweger mice reflects multiple neuronal defects induced by peroxisome deficiency. J. Comp. Neurol. 461, 394-413. doi: 10.1002/cne.10699

Faust, P. L., and Hatten, M. E. (1997). Targeted deletion of the PEX2 peroxisome assembly gene in mice provides a model for Zellweger syndrome, a human neuronal migration disorder. J. Cell Biol. 139, 1293-1305. doi: 10.1083/jcb.139.5.1293

Fernandez, A. G., Gunsalus, K. C., Huang, J., Chuang, L. S., Ying, N., Liang, H. L., et al. (2005). New genes with roles in the C. elegans embryo revealed using RNAi of ovary-enriched ORFeome clones. Genome Res. 15, 250-259. doi: 10.1101/gr. 3194805

Foley, J. E., Maeder, M. L., Pearlberg, J., Joung, J. K., Peterson, R. T., and Yeh, J. R. (2009). Targeted mutagenesis in zebrafish using customized zinc-finger nucleases. Nat. Protoc. 4, 1855-1867. doi: 10.1038/nprot.2009.209
Fransen, M., Nordgren, M., Wang, B., and Apanasets, O. (2012). Role of peroxisomes in ROS/RNS-metabolism: implications for human disease. Biochim. Biophys. Acta 1822, 1363-1373. doi: 10.1016/j.bbadis.2011.12.001

Fransen, M., Nordgren, M., Wang, B., Apanasets, O., and Van Veldhoven, P. P. (2013). Aging, age-related diseases and peroxisomes. Subcell. Biochem. 69, 45-65. doi: 10.1007/978-94-007-6889-5_3

Fujiki, Y., Matsuzono, Y., Matsuzaki, T., and Fransen, M. (2006). Import of peroxisomal membrane proteins: the interplay of Pex3p- and Pex19pmediated interactions. Biochim. Biophys. Acta 1763, 1639-1646. doi: 10.1016/j.bbamcr.2006.09.030

Gaiano, N., Amsterdam, A., Kawakami, K., Allende, M., Becker, T., and Hopkins, N. (1996). Insertional mutagenesis and rapid cloning of essential genes in zebrafish. Nature 383, 829-832. doi: 10.1038/383829a0

Galland, N., Demeure, F., Hannaert, V., Verplaetse, E., Vertommen, D., Van der Smissen, P., et al. (2007). Characterization of the role of the receptors PEX5 and PEX7 in the import of proteins into glycosomes of Trypanosoma brucei. Biochim. Biophys. Acta 1773, 521-535. doi: 10.1016/j.bbamcr.2007.01.006

Golling, G., Amsterdam, A., Sun, Z., Antonelli, M., Maldonado, E., Chen, W., et al. (2002). Insertional mutagenesis in zebrafish rapidly identifies genes essential for early vertebrate development. Nat. Genet. 31, 135-140. doi: 10.1038/ ng896

Gonczy, P., Echeverri, C., Oegema, K., Coulson, A., Jones, S. J., Copley, R. R., et al. (2000). Functional genomic analysis of cell division in C. elegans using RNAi of genes on chromosome III. Nature 408, 331-336. doi: 10.1038/35042526

Gonzalez, N. H., Felsner, G., Schramm, F. D., Klingl, A., Maier, U. G., and Bolte, K. (2011). A single peroxisomal targeting signal mediates matrix protein import in diatoms. PLoS ONE 6:e25316. doi: 10.1371/journal.pone. 0025316

Gould, S. J., McCollum, D., Spong, A. P., Heyman, J. A., and Subramani, S. (1992). Development of the yeast Pichia pastoris as a model organism for a genetic and molecular analysis of peroxisome assembly. Yeast 8, 613-628. doi: 10.1002/yea.320080805

Gressens, P., Baes, M., Leroux, P., Lombet, A., Van Veldhoven, P. P., Janssen, A., et al. (2000). Neuronal migration disorder in Zellweger mice is secondary to glutamate receptor dysfunction. Ann. Neurol. 48, 336-343. doi: 10.1002/15318249(200009)48:3<336::AID-ANA8>3.3.CO;2-H

Hofmann, A. F., Hagey, L. R., and Krasowski, M. D. (2010). Bile salts of vertebrates: structural variation and possible evolutionary significance. J. Lipid Res. 51, 226-246. doi: 10.1194/jlr.R000042

Horrocks, L. A., Sharma, M. (1982). "Plasmalogens and O-alkyl glycerophospholipids," in Phospholipids, eds J. N. Hawthorne and G. B. Anselleditors (Amsterdam: Elsevier), 51-93.

Huang, J., Viswakarma, N., Yu, S., Jia, Y., Bai, L., Vluggens, A., et al. (2011). Progressive endoplasmic reticulum stress contributes to Hepatocarcinogenesis in fatty acyl-CoA oxidase 1-deficient mice. Am. J. Pathol. 179, 703-713. doi: 10.1016/j.ajpath.2011.04.030

Hulshagen, L., Krysko, O., Bottelbergs, A., Huyghe, S., Klein, R., Van Veldhoven, P. P., et al. (2008). Absence of functional peroxisomes from mouse CNS causes dysmyelination and axon degeneration. J. Neurosci. 28, 4015-4027. doi: 10.1523/JNEUROSCI.4968-07.2008

Huybrechts, S. J., Van Veldhoven, P. P., Brees, C., Mannaerts, G. P., Los, G. V., and Fransen, M. (2009). Peroxisome dynamics in cultured mammalian cells. Traffic 10, 1722-1733. doi: 10.1111/j.1600-0854.2009.00970.x

Huyghe, S., Mannaerts, G. P., Baes, M., and Van Veldhoven, P. P. (2006a). Peroxisomal multifunctional protein-2: the enzyme, the patients and the knockout mouse model. Biochim. Biophys. Acta 1761, 973-994. doi: 10.1016/j.bbalip.2006.04.006

Huyghe, S., Schmalbruch, H., De Gendt, K., Verhoeven, G., Guillou, F., Van Veldhoven, P. P., et al. (2006b). Peroxisomal multifunctional protein 2 is essential for lipid homeostasis in Sertoli cells and male fertility in mice. Endocrinology 147, 2228-2236. doi: 10.1210/en.2005-1571

Ibabe, A., Bilbao, E., and Cajaraville, M. P. (2005). Expression of peroxisome proliferator-activated receptors in zebrafish (Danio rerio) depending on gender and developmental stage. Histochem. Cell Biol. 123, 75-87. doi: 10.1007/s00418004-0737-2

Janssen, A., Baes, M., Gressens, P., Mannaerts, G. P., Declercq, P., and Van Veldhoven, P. P. (2000). Docosahexaenoic acid deficit is not a major pathogenic factor in peroxisome-deficient mice. Lab. Invest. 80, 31-35. doi: 10.1038/labinvest. 3780005 
Joo, H. J., Kim, K. Y., Yim, Y. H., Jin, Y. X., Kim, H., Kim, M. Y., et al. (2010). Contribution of the peroxisomal acox gene to the dynamic balance of daumone production in Caenorhabditis elegans. J. Biol. Chem. 285, 29319-29325. doi: 10.1074/jbc.M110.122663

Joo, H. J., Yim, Y. H., Jeong, P. Y., Jin, Y. X., Lee, J. E., Kim, H., et al. (2009). Caenorhabditis elegans utilizes dauer pheromone biosynthesis to dispose of toxic peroxisomal fatty acids for cellular homoeostasis. Biochem. J. 422, 61-71. doi: 10.1042/BJ20090513

Kamath, R. S., Fraser, A. G., Dong, Y., Poulin, G., Durbin, R., Gotta, M., et al. (2003). Systematic functional analysis of the Caenorhabditis elegans genome using RNAi. Nature 421, 231-237. doi: 10.1038/nature01278

Kang, H. L., Benzer, S., and Min, K. T. (2002). Life extension in Drosophila by feeding a drug. Proc. Natl. Acad. Sci. U.S.A. 99, 838-843. doi: 10.1073/pnas.022631999

Kaplan, C. P., Thomas, J. E., Charlton, W. L., and Baker, A. (2001). Identification and characterisation of PEX6 orthologues from plants KAPLAN2001. Biochim. Biophys. Acta 1539, 173-180. doi: 10.1016/S0167-4889(01)00091-X

Kassmann, C. M., Lappe-Siefke, C., Baes, M., Brugger, B., Mildner, A., Werner, H. B., et al. (2007). Axonal loss and neuroinflammation caused by peroxisome-deficient oligodendrocytes. Nat. Genet. 39, 969-976. doi: 10.1038/ ng2070

Kassmann, C. M., Quintes, S., Rietdorf, J., Mobius, W., Sereda, M. W., Nientiedt, T., et al. (2011). A role for myelin-associated peroxisomes in maintaining paranodal loops and axonal integrity. FEBS Lett. 585, 2205-2211. doi: 10.1016/j.febslet.2011.05.032

Keane, M. H., Overmars, H., Wikander, T. M., Ferdinandusse, S., Duran, M., Wanders, R. J., et al. (2007). Bile acid treatment alters hepatic disease and bile acid transport in peroxisome-deficient PEX2 Zellweger mice. Hepatology 45, 982-997. doi: 10.1002/hep.21532

Kemp, S., Wei, H. M., Lu, J. F., Braiterman, L. T., McGuinness, M. C., Moser, A. B., et al. (1998). Gene redundancy and pharmacological gene therapy: implications for X-linked adrenoleukodystrophy. Nat. Med. 4, 1261-1268. doi: 10.1038/3242

Koch, J., Pranjic, K., Huber, A., Ellinger, A., Hartig, A., Kragler, F., et al. (2010). PEX11 family members are membrane elongation factors that coordinate peroxisome proliferation and maintenance. J. Cell Sci. 123, 3389-3400. doi: 10.1242/jcs.064907

Koepke, J. I., Nakrieko, K. A., Wood, C. S., Boucher, K. K., Terlecky, L. J., Walton, P. A., et al. (2007). Restoration of peroxisomal catalase import in a model of human cellular aging. Traffic 8, 1590-1600. doi: 10.1111/j.16000854.2007.00633.x

Koizumi, K., Higashida, H., Yoo, S., Islam, M. S., Ivanov, A. I., Guo, V., et al. (2007). RNA interference screen to identify genes required for Drosophila embryonic nervous system development. Proc. Natl. Acad. Sci. U.S.A. 104, 5626-5631. doi: 10.1073/pnas.0611687104

Kovacs, W. J., Tape, K. N., Shackelford, J. E., Wikander, T. M., Richards, M. J., Fliesler, S. J., et al. (2009). Peroxisome deficiency causes a complex phenotype because of hepatic SREBP/Insig dysregulation associated with endoplasmic reticulum stress. J. Biol. Chem. 284, 7232-7245. doi: 10.1074/jbc.M809064200

Krysko, O., Hulshagen, L., Janssen, A., Schutz, G., Klein, R., De, B. M., et al. (2007). Neocortical and cerebellar developmental abnormalities in conditions of selective elimination of peroxisomes from brain or from liver. J. Neurosci. Res. 85, 58-72. doi: 10.1002/jnr.21097

Krysko, O., Stevens, M., Langenberg, T., Fransen, M., Espeel, M., and Baes, M. (2010). Peroxisomes in zebrafish: distribution pattern and knockdown studies. Histochem. Cell Biol. 134, 39-51. doi: 10.1007/s00418-010-0712-Z

Li, X., Baumgart, E., Dong, G. X., Morrell, J. C., Jimenez-Sanchez, G., Valle, D., et al. (2002a). PEX11alpha is required for peroxisome proliferation in response to 4phenylbutyrate but is dispensable for peroxisome proliferator-activated receptor alpha-mediated peroxisome proliferation. Mol. Cell. Biol. 22, 8226-8240. doi: 10.1128/MCB.22.23.8226-8240.2002

Li, X., Baumgart, E., Morrell, J. C., Jimenez-Sanchez, G., Valle, D., and Gould, S. J. (2002b). PEX11 beta deficiency is lethal and impairs neuronal migration but does not abrogate peroxisome function. Mol. Cell. Biol. 22, 4358-4365. doi: 10.1128/MCB.22.12.4358-4365.2002

Maeda, I., Kohara, Y., Yamamoto, M., and Sugimoto, A. (2001). Large-scale analysis of gene function in Caenorhabditis elegans by high-throughput RNAi. Curr. Biol. 11, 171-176. doi: 10.1016/S0960-9822(01)00052-5

Managadze, D., Wurtz, C., Sichting, M., Niehaus, G., Veenhuis, M., and Rottensteiner, H. (2007). The peroxin PEX14 of Neurospora crassa is essential for the biogenesis of both glyoxysomes and Woronin bodies. Traffic 8, 687-68701. doi: 10.1111/j.1600-0854.2007.00560.x

Martens, K., Bottelbergs, A., Peeters, A., Jacobs, F., Espeel, M., Carmeliet, P., et al. (2012). Peroxisome deficient aP2-Pex 5 knockout mice display impaired white adipocyte and muscle function concomitant with reduced adrenergic tone. Mol. Genet. Metab. 107, 735-747. doi: 10.1016/j.ymgme.2012.10.015

Mast, F. D., Li, J., Virk, M. K., Hughes, S. C., Simmonds, A. J., and Rachubinski, R. A. (2011). A Drosophila model for the Zellweger spectrum of peroxisome biogenesis disorders. Dis. Model. Mech. 4, 659-672. doi: 10.1242/dmm.007419

Maxwell, M., Bjorkman, J., Nguyen, T., Sharp, P., Finnie, J., Paterson, C., et al. (2003). Pex13 inactivation in the mouse disrupts peroxisome biogenesis and leads to a Zellweger syndrome phenotype. Mol. Cell. Biol. 23, 5947-5957. doi: 10.1128/MCB.23.16.5947-5957.2003

Morais, S., Knoll-Gellida, A., Andre, M., Barthe, C., and Babin, P. J. (2007). Conserved expression of alternative splicing variants of peroxisomal acyl-CoA oxidase 1 in vertebrates and developmental and nutritional regulation in fish. Physiol. Genomics 28, 239-252. doi: 10.1152/physiolgenomics.00136.2006

Motley, A. M., Hettema, E. H., Ketting, R., Plasterk, R., and Tabak, H. F. (2000). Caenorhabditis elegans has a single pathway to target matrix proteins to peroxisomes. EMBO Rep. 1, 40-46. doi: 10.1093/embo-reports/kvd010

Müller, C. C., Nguyen, T. H., Ahlemeyer, B., Meshram, M., Santrampurwala, N., Cao, S., et al. (2011). PEX13 deficiency in mouse brain as a model of Zellweger syndrome: abnormal cerebellum formation, reactive gliosis and oxidative stress. Dis. Model. Mech. 4, 104-119. doi: 10.1242/dmm.004622

Nakayama, M., Sato, H., Okuda, T., Fujisawa, N., Kono, N., Arai, H., et al. (2011). Drosophila carrying pex3 or pex16 mutations are models of Zellweger syndrome that reflect its symptoms associated with the absence of peroxisomes. PLoS ONE 6:e22984. doi: 10.1371/journal.pone.0022984

Ortiz-Zarragoitia, M., Trant, J. M., and Cajaravillet, M. P. (2006). Effects of dibutylphthalate and ethynylestradiol on liver peroxisomes, reproduction, and development of zebrafish (Danio rerio). Environ. Toxicol. Chem. 25, 2394-2404. doi: 10.1897/05-456R.1

Peeters, A., Swinnen, J. V., Van Veldhoven, P. P., and Baes, M. (2011). Hepatosteatosis in peroxisome deficient liver despite increased betaoxidation capacity and impaired lipogenesis. Biochimie 93, 1828-1838. doi: 10.1016/j.biochi.2011.06.034

Petriv, O. I., Pilgrim, D. B., Rachubinski, R. A., and Titorenko, V. I. (2002). RNA interference of peroxisome-related genes in, C. elegans: a new model for human peroxisomal disorders. Physiol Genomics 10, 79-91. doi: 10.1152/ physiolgenomics.00044.2002

Ramos-Pamplona, M., and Naqvi, N. I. (2006). Host invasion during rice-blast disease requires carnitine-dependent transport of peroxisomal acetyl-CoA. Mol. Microbiol. 61, 61-75. doi: 10.1111/j.1365-2958.2006.05194.x

Rodemer, C., Thai, T. P., Brugger, B., Kaercher, T., Werner, H., Nave, K. A., et al. (2003). Inactivation of ether lipid biosynthesis causes male infertility, defects in eye development and optic nerve hypoplasia in mice. Hum. Mol. Genet. 12, 1881-1895. doi: 10.1093/hmg/ddg191

Rual, J. F., Ceron, J., Koreth, J., Hao, T., Nicot, A. S., Hirozane-Kishikawa, T., et al. (2004). Toward improving Caenorhabditis elegans phenome mapping with an ORFeome-based RNAi library. Genome Res. 14, 2162-2168. doi: 10.1101/gr. 2505604

Schumann, U., Wanner, G., Veenhuis, M., Schmid, M., and Gietl, C. (2003). AthPEX10, a nuclear gene essential for peroxisome and storage organelle formation during Arabidopsis embryogenesis. Proc. Natl. Acad. Sci. U.S.A. 100, 9626-9631. doi: 10.1073/pnas.1633697100

Sichting, M., Schell-Steven, A., Prokisch, H., Erdmann, R., and Rottensteiner, H. (2003). Pex7p and Pex20p of Neurospora crassa function together in PTS2dependent protein import into peroxisomes. Mol. Biol. Cell 14, 810-821. doi: 10.1091/mbc.E02-08-0539

Sieburth, D., Ch'ng, Q., Dybbs, M., Tavazoie, M., Kennedy, S., Wang, D., et al. (2005). Systematic analysis of genes required for synapse structure and function. Nature 436, 510-517. doi: 10.1038/nature03809

Simmer, F., Moorman, C., van der Linden, A. M., Kuijk, E., van den Berghe, P. V., Kamath, R. S., et al. (2003). Genome-wide RNAi of, C. elegans using the hypersensitive rrf-3 strain reveals novel gene functions. PLoS Biol. 1:E12. doi: 10.1371/journal.pbio.0000012

Sonnichsen, B., Koski, L. B., Walsh, A., Marschall, P., Neumann, B., Brehm, M., et al. (2005). Full-genome RNAi profiling of early embryogenesis in Caenorhabditis elegans. Nature 434, 462-469. doi: 10.1038/nature03353 
Soukupova, M., Sprenger, C., Gorgas, K., Kunau, W. H., and Dodt, G. (1999). Identification and characterization of the human peroxin PEX3. Eur. J. Cell Biol. 78, 357-374. doi: 10.1016/S0171-9335(99)80078-8

Spradling, A. C., Stern, D., Beaton, A., Rhem, E. J., Laverty, T., Mozden, N., et al. (1999). The Berkeley Drosophila Genome Project gene disruption project: single P-element insertions mutating 25\% of vital Drosophila genes. Genetics 153, 135-177

Thieringer, H., Moellers, B., Dodt, G., Kunau, W. H., and Driscoll, M. (2003). Modeling human peroxisome biogenesis disorders in the nematode Caenorhabditis elegans. J. Cell Sci. 116, 1797-1804. doi: 10.1242/jcs.00380

Thisse, B., Heyer, V., Lux, A., Alunni, V., Degrave, A., Seiliez, I., et al. (2004). Spatial and temporal expression of the zebrafish genome by large-scale in situ hybridization screening. Methods Cell Biol. 77, 505-519. doi: 10.1016/S0091679X(04)77027-2

Thoms, S., and Erdmann, R. (2005). Dynamin-related proteins and Pex11 proteins in peroxisome division and proliferation. FEBS J. 272, 5169-5181. doi: 10.1111/j.1742-4658.2005.04939.x

Titorenko, V. I., and Terlecky, S. R. (2011). Peroxisome metabolism and cellular aging. Traffic 12, 252-259. doi: 10.1111/j.1600-0854.2010.01144.x

Van Veldhoven, P. P. (2010). Biochemistry and genetics of inherited disorders of peroxisomal fatty acid metabolism. J. Lipid Res. 51, 2863-2895. doi: 10.1194/jlr.R005959

Venkatachalam, A. B., Lall, S. P., Denovan-Wright, E. M., and Wright, J. M. (2012). Tissue-specific differential induction of duplicated fatty acid-binding protein genes by the peroxisome proliferator, clofibrate, in zebrafish (Danio rerio). BMC Evol. Biol. 12:112. doi: 10.1186/1471-2148-12-112

Wanders, R. J., and Waterham, H. R. (2005). Peroxisomal disorders I: biochemistry and genetics of peroxisome biogenesis disorders. Clin. Genet. 67, 107-133. doi: 10.1111/j.1399-0004.2004.00329.x

Waterham, H. R., and Ebberink, M. S. (2012). Genetics and molecular basis of human peroxisome biogenesis disorders. Biochim. Biophys. Acta 1822, 1430-1441. doi: 10.1016/j.bbadis.2012.04.006

Weng, H., Ji, X., Naito, Y., Endo, K., Ma, X., Takahashi, R., et al. (2013). Pex11alpha deficiency impairs peroxisome elongation and division and contributes to nonalcoholic fatty liver in mice. Am. J. Physiol. Endocrinol. Metab. 304, E187-E196. doi: 10.1152/ajpendo.00425.2012

Yakunin, E., Moser, A., Loeb, V., Saada, A., Faust, P., Crane, D. I., et al. (2010). alpha-Synuclein abnormalities in mouse models of peroxisome biogenesis disorders. J. Neurosci. Res. 88, 866-876. doi: 10.1002/jnr.22246

Yokota, S., Togo, S. H., Maebuchi, M., Bun-Ya, M., Haraguchi, C. M., and Kamiryo, T. (2002). Peroxisomes of the nematode Caenorhabditis elegans: distribution and morphological characteristics. Histochem. Cell Biol. 118, 329-336. doi: 10.1007/s00418-002-0450-y

Zhang, G. F., Sadhukhan, S., Ibarra, R. A., Lauden, S. M., Chuang, C. Y., Sushailo, S., et al. (2012). Metabolism of gamma-hydroxybutyrate in perfused rat livers. Biochem. J. 444, 333-341. doi: 10.1042/BJ20112046

Zhou, B., Yang, L., Li, S., Huang, J., Chen, H., Hou, L., et al. (2012). Midlife gene expressions identify modulators of aging through dietary interventions. Proc. Natl. Acad. Sci. U.S.A. 109, E1201-E1209. doi: 10.1073/pnas. 1119304109

Conflict of Interest Statement: The authors declare that the research was conducted in the absence of any commercial or financial relationships that could be construed as a potential conflict of interest.

Received: 13 June 2013; accepted: 01 November 2013; published online: 22 November 2013.

Citation: Van Veldhoven PP and Baes M (2013) Peroxisome deficient invertebrate and vertebrate animal models. Front. Physiol. 4:335. doi: 10.3389/fphys.2013.00335

This article was submitted to Integrative Physiology, a section of the journal Frontiers in Physiology.

Copyright (c) 2013 Van Veldhoven and Baes. This is an open-access article distributed under the terms of the Creative Commons Attribution License (CC BY). The use, distribution or reproduction in other forums is permitted, provided the original author(s) or licensor are credited and that the original publication in this journal is cited, in accordance with accepted academic practice. No use, distribution or reproduction is permitted which does not comply with these terms. 